\title{
Aufzeichnung des Staatssekretärs Duckwitz
}

\section{St.S. 450/68 VS-vertraulich}

\section{Betr.: Besuch bei Secretary of State Dean Rusk ${ }^{1}$}

In dem am 29. Februar geführten Gespräch mit Herrn Rusk übergab ich zunächst den Brief des Herrn Bundesministers ${ }^{2}$, den Rusk aufmerksam durchlas und für den er sich bedankte. Er werde ihn bald beantworten. Meine Frage, ob er auf einzelne der in diesem Brief enthaltenen Punkte jetzt näher eingehen wolle, verneinte er. Es interessiere ihn heute lediglich zu erfahren, ob auf dem bevorstehenden Kongreß der SPD wiederum mit einer Anti-Vietnam-Resolution zu rechnen sei. ${ }^{3}$ Ich habe ihm darauf geantwortet, daß eine solche Möglichkeit nicht ausgeschlossen werden könne, daß aber der Herr Bundesminister zweifellos Anstrengungen unternehmen werde, um eine solche Resolution in vernünftigem Rahmen zu halten. Im übrigen liege ja, wie ihm bekannt sei, die Resolution des internationalen Sozialistenkongresses vom Oktober $^{4}$ vor, der sich die deutsche SPD nicht entziehen könne.

In diesem Zusammenhang erkundigte Rusk sich nach den Aussichten der NPD. Ich hielt es für richtig, ihm zu sagen, daß mit einem Einzug der NPD in den nächsten Bundestag gerechnet werden müsse, wobei die Anzahl der Mandate allerdings noch völlig offen sei. Ich hielte es persönlich nicht für ausge-

1 Staatssekretär Duckwitz hielt sich vom 26. bis 29. Februar 1968 in Washington auf. Zu den Gesprächen vgl. auch Dok. 77 und Dok. 84.

Zu den Gesprächen mit den beiden Sonderberatern des Präsidenten Johnson, McCloy und Walt W. Rostow, am 26. bzw. 27. Februar 1968 sowie mit weiteren Regierungsvertretern vgl. die Aufzeichnungen von Duckwitz vom 27., 28. und 29. Februar 1968; VS-Bd. 479 (Büro Staatssekretär); B 150, Aktenkopien 1968.

2 Am 22. Februar 1968 teilte Bundesminister Brandt dem amerikanischen Außenminister hinsichtlich des Vietnam-Kriegs mit: „Ich muß mich auch auf eine Auseinandersetzung einstellen, wenn der Parteitag meiner Partei Mitte März in Nürnberg zusammentritt. Dabei bin ich sicher, daß der Präsident und Sie nur zu froh wären, wenn eine politische Lösung gefunden würde, und daß Sie nicht erwägen, Atomwaffen einzusetzen. Ich habe in verschiedenen Reden vor einseitig-ungerechten Urteilen gewarnt und einigen meiner Landsleute geraten, sich nicht als Schulmeister des Weltgeschehens aufzuspielen. Es tut mir leid, daß gerade Berlin der Schauplatz unliebsamer Demonstrationen geworden ist." Vgl. Ministerbüro, Bd. 355 .

3 Zum Beschluß des SPD-Vorstands vom 5. Januar 1968 zu Vietnam vgl. Dok. 44, Anm. 4.

Vom 17. bis 21. März 1968 fand in Nürnberg der Bundesparteitag der SPD statt. In der EntschlieBung vom 20. März 1968 zur Lage in Vietnam wurde ausgeführt: „Das Lebensinteresse des vietnamesischen Volkes verlangt Waffenruhe und Frieden als Voraussetzung der Unabhängigkeit und Selbstbestimmung. Dazu gehört die Bereitschaft aller Beteiligten, auf eine militärische Lösung des Konflikts zu verzichten und eine politische Regelung anzustreben. Ein Verzicht der Vereinigten Staaten auf eine militärische Lösung würde unser Vertrauen in die Garantie der USA, ohne die es keine Sicherheit für Europa, die Bundesrepublik und Berlin gibt, nicht berühren." Vgl. PARTEITAG DER SOZIALDEMOKRATISCHEN PARTei DEUTSCHLANDS, S. $1069 \mathrm{f}$.

4 Vom 10. bis 13. Oktober 1967 tagte die Generalratskonferenz der Sozialistischen Internationale in Zürich. In einer Resolution wurde „an die Regierung Nordvietnams appelliert, ein Zeichen ihrer Bereitwilligkeit zu Friedensverhandlungen zu geben. Die Sozialistische Internationale ist der Ansicht, daß ein Friedensschluß den Abzug aller ausländischen Truppen aus Vietnam und eine Garantie der nationalen Unabhängigkeit des verarmten Landes mit sich bringen muß." Vgl. den Artikel „Die Sozialistische Internationale zu weltpolitischen Fragen“; NEUE Zürcher ZEITUNG, Fernausgabe, Nr. 283 vom 15. Oktober 1967, Bl. 1. 
schlossen, daß die NPD mit etwa 30 Abgeordneten in den Bundestag einziehen werde. Rusk meinte daraufhin, daß dies nicht nur sehr unliebsame Reaktionen in der Öffentlichkeit der Vereinigten Staaten hervorrufen werde, sondern auch die Sowjetunion zu neuen Attacken veranlassen würde.

Auf Rusks Bitte legte ich ihm die Grundzüge unserer Ostpolitik dar, der er in vollem Umfang zustimmte. Ebenso nahm er befriedigt von der Erklärung Kenntnis, daß wir nicht daran dächten, in der Berlin-Frage ohne ausgiebige Konsultationen mit unseren Verbündeten vorzugehen. Ich betonte bei dieser Gelegenheit, daß Meldungen amerikanischer Zeitungen, nach denen die Amerikaner nicht in den Besitz aller diesen Komplex betreffenden Fragen gekommen seien, nicht stimmten. Wir hätten nichts zu verbergen und würden auch in unserem eigenen Interesse die Amerikaner über jede Entwicklung genauestens unterrichten. Rusk riet in diesem Zusammenhang noch einmal zur Vorsicht bei den Unterhaltungen über die Gewaltverzichtserklärung, denn wir müßten damit rechnen, daß die Sowjets versuchten, uns in der einen oder der anderen mit der Gewaltverzichtserklärung zusammenhängenden Frage in eine Falle zu locken.

Staatssekretär Rusk ging dann dazu über - dies schien ihm das hauptsächliche Anliegen unserer heutigen Unterhaltung zu sein -, mir mit großer Eindringlichkeit die innenpolitische Entwicklung in den USA darzulegen. Präsident Johnson müsse jeden Tag erneut einen schweren Kampf gegen die Opposition im Senat und im Abgeordnetenhaus führen. Die Gefühle der Enttäuschung über die mangelnde Unterstützung durch die Bundesgenossen der USA seien nicht weit entfernt von Gefühlen der Erbitterung. Dies beziehe sich nicht nur auf die mangelnde materielle und moralische Unterstützung des Kampfes in Vietnam, sondern auch auf die Zurückhaltung der Verbündeten der USA, den USA in ihren finanziellen Schwierigkeiten zu helfen. Es komme hinzu, daß „der Mann auf der Straße“ geneigt sei, de Gaulle mit Europa zu identifizieren und die Abneigung, die zum Teil geradezu in $\mathrm{Ha}$ umschlage, gegen de Gaulle auf die Europäer schlechthin zu übertragen. Er selber wisse, daß diese Identifizierung ungerecht sei, und er möchte bei dieser Gelegenheit ausdrücklich betonen, daß die amerikanische Regierung für die deutsche Hilfe in Vietnam ${ }^{5}$ sehr dankbar sei. Aber gegen diese allgemeine Stimmung sei sehr schwer anzukämpfen. Eine Folge dieser Stimmung sei das Wiederaufkommen des Isolationismus alter Prägung. Es stehe nicht an, Senatoren wie Mansfield und Fulbright als Isolationisten zu bezeichnen (they are profound isolationists). Diese Bewegung werde wachsen und weitere Kreise ziehen. Schon heute müsse man mit einer Gefolgschaft der genannten Senatoren in Stärke von etwa 50 ihrer Kollegen rechnen.

Dean Rusk erklärte sodann, er halte es für seine Pflicht, die Freunde der USA in Europa auf diese Gefahr hinzuweisen. Sie könne in der Bevölkerung leicht überhand nehmen, zumal der Vietnamkrieg in seinem jetzigen Stadium erneute Opfer von der amerikanischen Bevölkerung verlange.

5 Die humanitäre Hilfe der Bundesrepublik umfaßte u.a. die Entsendung des Hospitalschiffs „Helgoland", den Einsatz des Malteser-Hilfsdienstes in Quang Nam, die Errichtung eines Jugenderziehungsheimes in Thu Duc und die Finanzierung von Gemeinschaftsanlagen in der Flüchtlingssiedlung Nam Hai. Vgl. Bulletin 1968, S. $200 \mathrm{f}$. 
Zum Abschluß des Gesprächs, das zum größten Teil unter vier Augen, später unter Hinzuziehung von Botschafter Knappstein und von Mr. Puhan stattfand, äußerte sich Dean Rusk sehr skeptisch über unsere Bemühungen, den Beitritt Englands in den Gemeinsamen Markt herbeizuführen. Er habe mit Interesse unsere vorsichtig optimistischen Äußerungen über die Pariser Konsultationsgespräche gelesen, könne aber selbst dieses Minimum von Optimismus nicht teilen. Wir würden erleben, daß die Franzosen sich den halben Zusagen, die sie gemacht hätten, wieder entziehen würden. Die USA stehe allerdings nach wie vor hinter den Bemühungen, den Beitritt Großbritanniens herbeizuführen, und werde auch ihrerseits nicht versäumen, den Engländern gut zuzureden, selbst auf kleine Konzessionen einzugehen, aber er könne es eigentlich nicht mit gutem Gewissen tun, da in dieser Frage das Nein de Gaulles seiner Auffassung nach unerschütterlich sei.

Abschließend bat mich der Staatssekretär, dem Herrn Bundesminister seine besten Grüße und Wünsche zu übermitteln. Er hoffe, daß der Herr Bundesminister seine Andeutung, im Frühjahr nach New York zu kommen, wahrmachen werde, damit er dann Gelegenheit habe, sich mit ihm wieder einmal ausführlich zu unterhalten.

Hiermit dem Herrn Bundesminister ${ }^{6}$ vorgelegt.

Duckwitz

VS-Bd. 479 (Büro Staatssekretär)

\section{Aufzeichnung des Staatssekretärs Duckwitz}

\section{St.S. 442 I/68 geheim}

1. März 1968

Bei meinem Besuch ${ }^{1}$ bei Under Secretary Eugene Rostow am 29.2.1968 äuBerte dieser sich befriedigt über seine Gespräche in Bonn ${ }^{3}$. Insbesondere sei die deutsche Anregung zur Verkürzung der Kennedy-Runde nützlich gewesen. Die Fortschritte in der Frage der Zahlungsbilanz seien zur Zeit für die psychologische und politische wie auch die wirtschaftliche Situation in den USA von

6 Hat Bundesminister Brandt am 7. März 1968 vorgelegen.

1 Staatssekretär Duckwitz hielt sich vom 26. bis 29. Februar 1968 in den USA auf.

2 Am 4. März 1968 notierte Staatssekretär Duckwitz ergänzend für Ministerialdirektor Harkort: „In meinem kürzlichen Gespräch mit Eugene Rostow wurden auch Möglichkeiten erörtert, wie die Bundesrepublik die USA in ihrer zur Zeit bedrängten Situation finanziell entlasten könne. Rostow wies auf folgende Möglichkeiten hin: 1) Beschleunigung der Kennedy-Runde. Ich habe ihn darüber unterrichtet, daß die Franzosen diesem Gedanken ablehnend gegenüberstehen. 2) Vergrößerung unserer Türkeihilfe. Eine Entlastung der Amerikaner, die ihr eigenes Programm wahrscheinlich kürzen werden, würde dankbar begrüßt. 3) Deutsche und Amerikaner sollten in einem wirtschaftlichen Stabilisierungsprogramm im Nahen Osten zusammenwirken. Es gäbe hier Gemeinschaftsprojekte, die lohnend seien und die von den Amerikanern nicht allein durchgeführt werden könnten." Vgl. VS-Bd. 505 (Büro Staatssekretär); B 150, Aktenkopien 1968.

3 Für das Gespräch mit Bundeskanzler Kiesinger am 12. Februar 1968 vgl. Dok. 53. 
besonderer Bedeutung und würden wichtige Rückwirkungen auf die Einstellung von Öffentlichkeit und Kongreß gegenüber Europa haben. Man sehe den weiteren Gesprächen mit der Bundesregierung in dieser Hinsicht mit Erwartung entgegen. Ich gab der Hoffnung Ausdruck, daß man eine beide Seiten zufriedenstellende Regelung erzielen werde und betonte, daß wir uns der Bedeutung dieser Frage bewußt seien.

Rostow unterstrich die Notwendigkeit des Ausbaus der politischen Wirkungsmöglichkeiten der NATO - z.B. hinsichtlich einer Stabilisierung der Lage im Mittelmeerraum. Auch in diesem Zusammenhang sei es wichtig, daß die USA nicht das Gefühl hätten, allein zu stehen, da sich sonst eine gewisse Tendenz zum Isolationismus verstärken könnte. Ich entgegnete, daß unsere Beurteilung der Lage im Mittelmeer der amerikanischen entspräche. Wir seien über die Vergrößerung des russischen Einflusses in diesem Gebiet sehr besorgt. Ich hätte jedoch gehört, daß die Ägypter über die Sowjets in letzter Zeit enttäuscht seien. Mr. Rostow entgegnete, daß die Sowjets zahlenmäßig in Ägypten sehr stark vertreten seien; es sei schwer abzuschätzen, wie stark ihre tatsächliche Kontrolle über die noch vorhandenen prowestlichen Elemente in der Regierung sei. Man müsse jedoch befürchten, daß ihre Kontrolle zunähme. Die weitere Entwicklung im Verhältnis Ägyptens zu den Vereinigten Staaten werde einen Hinweis dafür geben, ob Nasser noch wirkliche Handlungsfreiheit habe. Auf jeden Fall sei es sehr wichtig, daß Europa und ganz besonders die Bundesrepublik bei gemeinschaftlichen Aktionen der NATO-Mächte zur Stabilisierung des Nahen Ostens tatkräftig mitarbeiten. Ich entgegnete, daß wir hierzu durchaus bereit seien. Zum Beispiel hätten wir kürzlich fünfzig Millionen DM für arabische Flüchtlinge zur Verfügung gestellt. ${ }^{4}$

Zum Nichtverbreitungsvertrag erwähnte ich das Memorandum, das wir demnächst in Genf einreichen würden ${ }^{5}$ und betonte unsere drei hauptsächlichen Forderungen ${ }^{6}$ für eine weitere Verbesserung des Vertragsentwurfs. Rostow erklärte, daß die amerikanische Regierung bereit sei, alle noch ungeklärten Punkte zu regeln; es gäbe jedoch wohl keine großen Meinungsverschiedenheiten mehr zwischen den beiden Regierungen über den Vertrag.

Gesandter von Lilienfeld wies auf Presseberichte aus Brüssel hin, nach denen die Vereinigten Staaten angeblich auf EURATOM Druck auszuüben versuchten durch die Drohung, daß sie Uranlieferungen an die Länder zurückhalten würden, die dem Vertrag nicht beitreten. Obgleich der Sprecher der Bundesregierung diese Berichte dementiert hätte, seien derartige Meldungen doch da$\mathrm{zu}$ angetan, das Unbehagen in Deutschland über den Vertrag zu vergrößern. Rostow erwiderte, daß die Amerikaner nicht daran dächten, derartige Methoden anzuwenden und daß seines Wissens die Frage der Uranbelieferung bilateral und zufriedenstellend geregelt werde. Ich griff dann die Frage einer nuklearen Garantie durch die Amerikaner auf. Die Bundesrepublik würde gern etwas Stärkeres haben als die NATO-Garantie, zumal die Laufzeit der beiden

\footnotetext{
4 Zum Kabinettsbeschluß vom 20. September 1968 vgl. Dok. 50, Anm. 6.

5 Zum Memorandum der Bundesregierung, das bei der Konferenz der 18-Mächte-Abrüstungskommission am 6. März 1968 vorgelegt wurde, vgl. Dok. 98, Anm. 2.

6 Vgl. dazu Dok. 65 .
} 
Verträge $^{7}$ ungleich sei. Eine feierliche Erklärung des amerikanischen Präsidenten würde uns auch innenpolitisch sehr nützlich sein. Staatssekretär Rostow entgegnete zunächst mit der bekannten amerikanischen Stellungnahme, daß der NATO-Vertrag eine ausreichende Garantie darstelle, schien jedoch im weiteren Verlauf des Gesprächs an dem Gedanken einer Erklärung des Präsidenten Interesse zu finden und sagte zu, diesen Vorschlag zu prüfen. (Ein entsprechendes Schreiben mit einem informellen Vorschlag für eine etwaige Erklärung des Präsidenten wird ihm gesondert übergeben. ${ }^{8}$ )

Ich meinte abschließend, daß die Nichtverbreitung von Nuklearwaffen im Prinzip von der Bundesregierung begrüßt werde, daß jedoch noch gewisse Schwierigkeiten bei uns bestünden. Auf die Frage, ob Indien und Japan unterzeichnen würden, sagte Rostow, er sei sicher, daß Japan unterzeichnen werde. Auch Indien werde seines Erachtens mitmachen. Dies hätte z. B. Frau Gandhi noch kürzlich Kossygin gesagt. Die Frage der Sicherheitsgarantie sei jedoch für Indien ein größeres Problem als für NATO-Mitgliedstaaten.

Hiermit dem Herrn Minister ${ }^{9}$ vorgelegt.

Duckwitz

\section{VS-Bd. 479 (Büro Staatssekretär)}

7 In Artikel 13 des NATO-Vertrags vom 4. April 1949 war eine zwanzigjährige Geltungsdauer festgelegt, und Artikel X, Absatz 2 des amerikanisch-sowjetischen Entwurfs vom 18. Januar 1968 für ein Nichtverbreitungsabkommen sah eine Revisionskonferenz nach 25 Jahren vor. Vgl. dazu Dok. 21, Anm. 14, und Dok. 67, Anm. 14.

8 Dieser Satz wurde von Staatssekretär Duckwitz hervorgehoben. Dazu handschriftliche Bemerkung: „Siehe Anlage."

Mit Schreiben vom 29. Februar 1968 teilte Duckwitz dem Staatssekretär im amerikanischen Außenministerium, Eugene Rostow, mit: „We have complete confidence in the United States' determination to uphold the Atlantic Alliance for an unlimited period and to safeguard Europe's security with all necessary means. The Federal Government, too, is equally resolved to adhere to the Atlantic Alliance. Yet it cannot be ruled out that during the extremely long duration of the NonProliferation Treaty (at least 25 years) undesirable developments might intervene which we cannot now foresee. We, therefore, consider it desirable that the United States should reaffirm in connexion with the signing of the Non-Proliferation Treaty its determination to keep nuclear and conventional forces ready for the defense of Europe, as long as this is necessary and desired by America's European Allies. This could be done in the form of a solemn declaration by the President of the United States.“ Duckwitz fügte dem Schreiben den Entwurf einer solchen Erklärung bei: „On the occasion of the conclusion of the Non-Proliferation Treaty the US Government wishes to reaffirm that it is determined and prepared to contribute to the defense of Europe by maintaining troops stationed in Europe and by keeping available nuclear forces in Europe and in the United States as long as this is necessary and requested by its European Allies." Vgl. VS-Bd. 479 (Büro Staatssekretär); B 150, Aktenkopien 1968.

Am 4. März 1968 übergab Gesandter von Lilienfeld, Washington, das Schreiben „mit dem Vorschlag einer Formulierung für eine etwaige Garantieerklärung des Präsidenten“ im amerikanischen Außenministerium. Eugene Rostow bezeichnete die Schriftstücke „als ,very helpful'. Man werde sie sorgfältig studieren; er glaube, daß man einen entsprechenden Vorschlag dem Präsidenten vorlegen könne." Vgl. den Drahtbericht Nr. 459 des Botschafters Knappstein, Washington; VSBd. 4348 (II B 1); B 150, Aktenkopien 1968.

9 Hat Bundesminister Brandt am 7. März 1968 vorgelegen. 


\section{Aufzeichnung des Botschafters z.b.V. Böker}

I B 5-82.00-92.08-323/68 geheim

Betr.: Deutsch-chinesische Beziehungen

Anläßlich der Konsultationsgespräche zwischen dem Herrn Bundeskanzler und General de Gaulle am 16. Februar habe ich Herrn Puaux auf die Angelegenheit angesprochen und ihn an das Gespräch erinnert, das ich am 7. April 1967 mit dem Gesandten Manac'h gehabt hatte. ${ }^{1}$ Herr Puaux war über die Angelegenheit nicht orientiert, zeigte aber großes Interesse. Ich erklärte ihm, daß die Angelegenheit bei uns aus administrativen Gründen zögerlich behandelt worden sei. ${ }^{2}$ Das Auswärtige Amt habe aber mit Interesse von dem Gespräch Kenntnis genommen, das zwischen Herrn Manac'h und dem rumänischen Botschafter in Paris über die deutsch-chinesischen Beziehungen stattgefunden hatte. Wir würden es begrüßen, wenn auf demselben Kanal (Manac'h-rumänischer Botschafter ${ }^{3}$-chinesischer Botschafter in Paris ${ }^{4}$ ) die Nachricht zurückgespielt werden könnte, daß wir an den chinesischen Äußerungen interessiert seien. Wir wären dankbar, wenn wir dann über eine eventuelle Reaktion unterrichtet werden könnten.

Herr Puaux versprach, dies in die Wege zu leiten. Er sagte, eine gewisse Schwierigkeit bestünde darin, daß der damalige rumänische Botschafter Dimitriu (?), der das Gespräch mit Herrn Manac'h vermutlich geführt habe, nicht mehr in Paris sei. Er sehe aber keinen Hinderungsgrund, das Gespräch auch mit seinem Nachfolger zu führen. Dies sei vielleicht sogar von Vorteil, da Herr

1 Am 11. April 1967 notierte Ministerialdirigent Böker dazu: „Anläßlich der Konsultationsgespräche, die ich am 7. April über Fern-Ost-Fragen mit dem Leiter der Fern-Ost-Abteilung des Quai d'Orsay, Gesandten Manac'h, in Bonn gefüht habe, nahm mich Herr Manac'h beiseite und machte mir, mit der Bitte um streng vertrauliche Behandlung, folgende Mitteilung: Der rumänische Botschafter in Paris habe ihm neulich im Laufe eines Tour d'horizon von einem Gespräch berichtet, das er vor kurzem mit dem chinesischen Botschafter in Paris geführt hatte. Dieser habe mit auffallendem Nachdruck von dem Interesse Chinas an Beziehungen zur Bundesrepublik Deutschland gesprochen. Er habe gesagt, die deutsch-chinesischen Wirtschaftsbeziehungen entwickelten sich sehr erfreulich; man sei in Peking aber auch an einer Weiterentwicklung der deutsch-chinesischen Beziehungen interessiert. Man denke dabei nicht nur an die gegenseitige Errichtung von Handelsvertretungen, sondern auch, darüber hinaus'. Herr Manac'h hatte den Eindruck, daß der rumänische Botschafter ihm diese Mitteilung nicht von ungefähr gemacht habe. ${ }^{4}$ Dazu vermerkte Bundesminister Brandt am 16. April 1967 handschriftlich: „Nicht unbeachtet lassen. Sehr behutsam behandeln. Zunächst nur mit Blick auf Handelsvertretungen." Vgl. VS-Bd. 2821 (I B 4); B 150, Aktenkopien 1967.

2 Am 1. März 1968 vermerkte Botschafter z.b.V. Böker, daß Staatssekretär Lahr ihn ,im Spätherbst 1967“ auf die Angelegenheit angesprochen habe. Lahr habe ausgeführt, daß die Aufzeichnung vom 11. April 1967 ,in einem Aktenstoß liegen geblieben" sei, und habe gebeten, den Ball über den Unterabteilungsleiter im französischen Außenministerium, Manach, an die „chinesische Seite zurückzuspielen“. Er, Böker, habe seinerzeit darauf hingewiesen, „daß dies in unauffalliger Weise“ nur anläßlich der ${ }_{n}$ nächsten Konsultationsbesprechungen in Paris, d. h. nicht vor Ende Januar 1968 erfolgen könne“. Vgl. VS-Bd. 2821 (I B 4); B 150, Aktenkopien 1968.

3 Constantin Flitan.

4 Huang Chen. 
Dimitriu seinem Temperamente nach zu gewissen Übertreibungen geneigt habe.

Ich fügte hinzu, daß wir daran interessiert seien, daß die Mitteilung an die chinesische Seite unauffällig und geräuschlos erfolge und in einer Form, die keine falschen Erwartungen erwecke.

Hiermit dem Herrn Staatssekretär ${ }^{5}$ vorgelegt.

Böker

VS-Bd. 2821 (I B 4)

\section{9}

\section{Aufzeichnung des Ministerialdirektors Ruete}

II A 4-82.00-94.29-313/68 geheim

4. März 1968 1

Betr.: Gewaltverzicht

Mit Schreiben des Herrn Staatssekretärs vom 9.2.1968 war dem Herrn Staatssekretär des Bundeskanzleramts der Entwurf einer deutschen Antwort auf die sowjetischen Memoranden über den Gewaltverzicht übermittelt worden. ${ }^{2}$ Text dieses Entwurfs ist in der Anlage beigefügt. ${ }^{3}$

In den folgenden Darlegungen werden zunächst die vermutlichen Motive der sowjetischen Politik und die Überlegungen entwickelt, die für unsere Haltung maßgebend sein können. Schließlich werden Vorschläge für unser weiteres Verhalten gemacht.

I. Sowjetische Politik

1) Die Sowjets beabsichtigen anscheinend, auf dem Wege über den Gewaltverzicht einen großen Teil ihrer Forderungen in der Deutschlandpolitik durchzusetzen, wobei sie zunächst wohl von einem Maximalprogramm ausgehen. $\mathrm{Ob}$ die Sowjets tatsächlich annehmen, daß sie auf diesem Wege einer Friedensregelung vorgreifen und damit einen ihnen noch günstigeren Status quo erreichen können, läßt sich noch nicht klar erkennen. Wenn dem so wäre, dann ließe es sich vorstellen, daß sie auch mit Teilerfolgen zufrieden sein würden, so daß Raum für wirkliche Verhandlungen bliebe.

5 Hat den Staatssekretären Lahr und Duckwitz am 3. bzw. 4. März 1968 vorgelegen.

1 Die Aufzeichnung wurde von Ministerialdirigent Sahm konzipiert.

2 Zum Schreiben des Staatssekretärs Duckwitz an Staatssekretär Carstens, Bundeskanzleramt, vgl. Dok. 39, Anm. 1.

Zu den sowjetischen Memoranden vom 12. Oktober und 21. November 1967 vgl. Dok. 23, Anm. 2, bzw. Dok. 11, Anm. 3.

3 Dem Vorgang nicht beigefügt.

Für den Entwurf eines Aide-mémoires vom 31. Januar 1968 vgl. Dok. 39. 
Es ist aber auch denkbar, daß sie der deutschen aktiven Ostpolitik ein neues Hindernis entgegenstellen wollen, indem sie die Vereinbarung eines Gewaltverzichts - wohlgemerkt nicht nur mit ihnen, sondern mit sämtlichen osteuropäischen Staaten und der Zone - von einer Reihe für uns unannehmbarer Bedingungen abhängig machen. Bedingungen übrigens, die über die berühmten drei Voraussetzungen für die „Normalisierung“4 hinausgehen.

2) In diesem Zusammenhang ist es bemerkenswert, da $\beta$ der sowjetische Botschafter bei der Übergabe des letzten Memorandums vom 29.1.1968 nachdrücklich gefordert hat, die Verhandlungen mit der Sowjetunion über Gewaltverzicht müßten in zeitlichem Zusammenhang mit unseren Verhandlungen mit den übrigen Mitgliedern des Warschauer Paktes über Gewaltverzicht stehen. ${ }^{5}$ Da es nicht vorstellbar ist, daß wir gleichzeitig mit sieben Regierungen Verhandlungen führen, müssen wir eines Tages mit dem Vorschlag rechnen, wir sollten doch die Verhandlungen in einer Konferenz zusammenfassen, an der alle interessierten Länder teilnehmen könnten. Wir werden deswegen sehr sorgfältig darauf achten müssen, daß der bilaterale Charakter der Gespräche erhalten bleibt.

3) Dabei muß klargestellt werden, daß sowohl die Bundesregierung wie die anderen Mitglieder des Warschauer Paktes frei sein müssen, untereinander die einzelnen bilateralen Erklärungen über den Gewaltverzicht je nach den Umständen des Falles im gemeinsamen Einvernehmen auszugestalten und diejenigen Fragen zu bestimmen, über die bei den Verhandlungen über den Gewaltverzicht auch noch Einvernehmen erzielt werden soll.

Dies ist nicht nur wegen der abweichenden Probleme nötig, die zwischen uns und den einzelnen Ländern liegen (Oder/Neiße; Münchener Abkommen usw.), sondern vor allem auch im Hinblick auf unser Verhältnis zur „DDR“. Eine völkerrechtliche Form für den Austausch von Gewaltverzichtserklärungen mit dem anderen Teil Deutschlands kommt nicht in Betracht. Wir sehen vielmehr in einem etwaigen innerdeutschen Gewaltverzicht eine Voraussetzung für die Annäherung beider Teile Deutschlands, sozusagen die "Geschäftsgrundlage“ des Einigungsprozesses. Er ist nicht dem üblichen zwischenstaatlichen Gewaltverzicht gleichzusetzen, wie er in Artikel 2 der UN-Satzung niedergelegt ist. Die Beziehungen beider Teile Deutschlands zueinander sind auch nach Auffassung der Verantwortlichen in Ostberlin gekennzeichnet durch die Tatsache, daß die deutsche Nation fortbesteht und daß es sich beide Teile zur nationalen Pflicht gemacht haben, die Annäherung und Einigung herbeizuführen.

4 Am 1. September 1966 nannte Ministerpräsident Cyrankiewicz in einer Rede in Warschau als Vorbedingungen für eine Normalisierung des Verhältnisses zwischen der Bundesrepublik und Polen die „Anerkennung der Grenzen und Verzicht auf sämtliche territoriale Ansprüche; Anerkennung der Deutschen Demokratischen Republik und Anknüpfung gegenseitiger Beziehungen unter Achtung der Souveränität und territorialen Unantastbarkeit“ sowie den „Verzicht auf jegliches Streben nach Kernwaffen“. Vgl. DzD IV/12, S. 1281.

Dieser Forderungen wurden in der Erklärung der kommunistischen und Arbeiterparteien Europas „Für den Frieden und die Sicherheit in Europa“ wiederholt, die auf der Konferenz von Karlový Varý (Karlsbad) vom 24. bis 26. April 1967 verabschiedet wurde. Für den Wortlaut der „Karlsbader Beschlüsse“ vgl. DzD V/1, S. 1047-1054.

5 Für das Gespräch des Staatssekretärs Duckwitz mit dem sowjetischen Botschafter Zarapkin am 29. Januar 1968 vgl. Dok. 32. 
Dies bringt der Entwurf der neuen Verfassung der „DDR“ vom 31.1.19686 klar zum Ausdruck.

Wir glauben ferner, davon ausgehen zu können, daß auch auf seiten der osteuropäischen Partner Sympathien für die größtmögliche Entscheidungsfreiheit hinsichtlich der Ausgestaltung der einzelnen Gewaltverzichtserklärungen bestehen.

4) Sicherlich ist in der sowjetischen Führungsspitze und in den Führungsgremien in Osteuropa die Ansicht verbreitet, die Bundesregierung stehe unter dem Zwang der Verhältnisse vor einem grundsätzlichen Kurswechsel in ihrer Ostpolitik.

Gerade deshalb ist es jetzt besonders wichtig, in Gesprächen zu klären, daß unsere Entspannungspolitik nicht Kapitulation bedeutet, sondern Entspannung ein Entgegenkommen auf beiden Seiten voraussetzt. Wenn die Sowjetregierung und ihre besonders intransigenten Verbündeten einsehen, daß es verfehlt und vergeblich ist, die Bundesrepublik Deutschland unter Druck setzen oder isolieren zu wollen, werden sachliche Gespräche möglich sein.

Dabei sind wir uns klar, daß solche Gespräche immer nur an der Peripherie bleiben können und daß sie für die Lösung der fundamentalen Fragen der Deutschlandpolitik und der Europäischen Sicherheit weder zum richtigen Zeitpunkt stattfinden noch das geeignete Forum bieten.

II. Deutsche Haltung

1) Politik des Gewaltverzichts

Die der deutschen Politik des Gewaltverzichts zugrundeliegenden Gedanken sind in Teil I des Antwort-Entwurfs ausführlich dargelegt.

Es wäre allerdings nützlich, außer den erwähnten allgemeinpolitischen Gründen noch auf spezifische deutsche Sicherheitsinteressen hinzuweisen, um den Eindruck zu vermeiden, als ob nur von den Deutschen eine Gefahr ausginge. Hierfür eignete sich ein Hinweis auf die allgemeine Steigerung der Rüstungsausgaben in den Haushaltsvoranschlägen für 1968 aller Mitglieder des Warschauer Pakts (allein die Zone um mehr als $60 \%$ gegenüber dem Vorjahr). Dieser Steigerung stehen auf westlicher Seite Verringerungen sowohl der Streitkräfte wie bei der Haushaltsentwicklung gegenüber, so daß sie jedenfalls nicht durch eine Verstärkung der NATO gerechtfertigt sind; in diesen Steigerungen der Rüstungsausgaben in allen Ländern Osteuropas liegt daher eine erhebliche Bedrohung der Bundesrepublik Deutschland und ihrer Verbündeten.

Der Antwort-Entwurf könnte in diesem Sinne ergänzt werden.

2) Gewaltverzicht gegenüber der Sowjetunion

Die Bundesrepublik Deutschland hat in völkerrechtlich verbindlicher Form gegenüber den Westmächten auf die Anwendung oder Androhung von Gewalt verzichtet (vgl. Teil II des Antwort-Entwurfs).

Es bestehen weder rechtliche noch politische Schwierigkeiten, diese Formulierungen ganz oder teilweise in einem gegenseitigen Gewaltverzicht mit der Sowjetunion zu wiederholen.

6 Zu dem Entwurf vgl. Dok. 60, Anm. 11. 
3) Verbindung mit anderen Fragen

Die Sowjets haben die Frage des Gewaltverzichts mit folgenden weiteren Punkten verbunden:

a)

- Verzicht auf Zugang zu nuklearen Waffen in direkter oder indirekter Form (oder Beitritt zu NV-Vertrag);

- Achtung des Status von West-Berlin als besonderer politischer Einheit;

- Anerkennung des Münchener Abkommens „ex tunc“ (nicht vordringlich);

- Anerkennung der Unverletzlichkeit der in Europa bestehenden Grenzen (einschließlich jener der „DDR“);

- Ergreifung wirksamer Maßnahmen, um die Entwicklung des Militarismus und des Nazismus auf Territorium der Bundesrepublik Deutschland nicht zuzulassen;

- Verzicht auf „Alleinvertretungsanspruch“.

b) Sowjetunion geht davon aus, daß Potsdamer Abmachungen bindendes Recht für Bundesrepublik Deutschland darstellen, und daß Art. 53 Ziff. 1 und 107 der UN-Charta heute noch gültiges Recht sind und der Sowjetunion auch im Falle eines Gewaltverzichts ein militärisches Interventionsrecht gegen die Bundesrepublik Deutschland gewähren.

c) Sowjetunion verlangt von der Bundesregierung

- Definition ihrer Haltung zu den unter a) genannten Punkten;

- Einverständnis, mit allen Mitgliedern des Warschauer Paktes, einschließlich der „DDR“, ähnliche Erklärungen über Gewaltverzicht in völkerrechtlicher Form auszutauschen (angeblich haben Sowjets bereits in diesem Sinne mit ihren Verbündeten Fühlung genommen);

- Verhandlungen mit den Mitgliedern des Warschauer Paktes in zeitlichem Zusammenhang mit denjenigen mit Moskau.

Obwohl alle diese Fragen mit einem Gewaltverzicht in keinem sachlichen oder logischen Zusammenhang stehen, erscheint es angebracht, nicht von vornherein jede Diskussion abzulehnen. Einmal müssen wir vermeiden, daß uns der zwar ungerechtfertigte, aber wirkungsvolle Vorwurf gemacht wird, wir lehnten Verhandlungen über Gewaltverzicht „und damit zusammenhängende Fragen“ ab. Zum anderen handelt es sich um Themen, die seit Jahren Gegenstand der Diskussion in Ost und West sind. Wenn wir sie auch nicht alle in bilateralen Verhandlungen zwischen uns und der Sowjetunion und/oder den osteuropäischen Staaten lösen können, so sollten wir andererseits einem Gespräch darüber nicht ausweichen. Bei den Verhandlungen über die Harmel-Studie ${ }^{7}$ ist es deutlich erkennbar geworden, daß auch unsere Verbündeten eine Klärung der deutschen Haltung zu den meisten dieser Fragen erwarten.

Wenn wir aber bereit sind, diese (oder weitere) Fragen in das Gespräch einzubeziehen, dann sollten wir dies nicht nur in allgemeinen Ausführungen zu erkennen geben, sondern unseren Standpunkt zu den einzelnen Punkten bereits

7 Für den Wortlaut des „Berichts des Rats über die künftigen Aufgaben der Allianz“ (Harmel-Bericht), der dem Kommuniqué über die NATO-Ministerratstagung am 13./14. Dezember 1967 beigefügt war, vgl. EUROPA-ARCHIV 1968, D 75-77. 
in der Antwort an die Sowjets andeuten. Dies empfiehlt sich aus folgenden Gründen:

- Die Sowjets haben ihrerseits ihre Positionen dargelegt; wir sollten ihnen unsere Positionen entgegenhalten, da wir ihnen sonst die Initiative überlassen;

- Wenn wir unsere Position klar darlegen, haben wir einen guten Ausgangspunkt für etwaige Gespräche und Verhandlungen;

- Gegenüber unseren Verbündeten, aber auch bei einer späteren möglicherweise notwendig werdenden Veröffentlichung, wird deutlich, daß wir der Diskussion nicht ausgewichen sind;

- Nur durch ein Eingehen auf die zusätzlichen Punkte ist es möglich, auch unsererseits zusätzliche Fragen anzuschneiden.

In Teil III des Antwort-Entwurfs ist aus diesen Gründen eine knappe Darstellung des Standpunktes der Bundesregierung zu den einzelnen, von der Sowjetunion angeschnittenen Fragen enthalten. Weniger zu sagen oder gar einzelne Punkte fortzulassen, würde neue Probleme aufwerfen und für uns nachteilig sein, weil die vorgenannten Argumente für ein Eingehen auf die sowjetischen Punkte nicht berücksichtigt wurden.

Wenn wir auf diese zusätzlichen Punkte eingehen, wäre allerdings klarzustellen, daß sie keine Bedingung oder Voraussetzung für den Austausch von Gewaltverzichtserklärungen sein dürfen. Der Gewaltverzicht bleibt aber auch sinnvoll und notwendig, wenn eine Einigung über die Punkte nicht erzielt werden kann. Der Entwurf könnte deswegen dahin ergänzt werden, daß die Bundesregierung nicht annehme, die Sowjets lehnten einen Austausch von Gewaltverzichtserklärungen $\mathrm{ab}$, wenn es zu keiner Einigung über die genannten Punkte komme. Denn aus einer solchen Ablehnung müsse geschlossen werden, daß die Sowjets sich in einem solchen Fall die Gewaltanwendung vorbehielten.

4) Verbindung mit NV-Vertrag

Seit den sowjetischen Memoranden zum Gewaltverzicht und der Arbeit an dem Antwort-Entwurf ist ein neuer Tatbestand eingetreten: die amerikanisch-sowjetische Einigung über die Vorlage gleichlautender Entwürfe für einen Atomsperrvertrag durch die beiden Ko-Präsidenten der Genfer Abrüstungskonferenz. ${ }^{8}$ Es muß damit gerechnet werden, daß dieser Vertrag in absehbarer Zeit - in im wesentlichen unveränderter Fassung - zur Unterzeichnung aufliegen wird.

Die atomaren Machtmittel der Kernwaffenstaaten bleiben unberührt. Mit einer verbindlichen Verpflichtung der Kernwaffenstaaten zu nuklearen Abrüstungsmaßnahmen ist nicht zu rechnen. Auch ist es unwahrscheinlich, daß eine Bestimmung über das Verbot von Drohung, politischen Drucks oder politischer Erpressung seitens der Kernwaffenstaaten gegenüber den Nicht-Kernwaffenstaaten in den Vertrag eingefügt wird. Damit behielte die Sowjetunion ein Machtmittel in der Hand, das sie jederzeit gegen die Bundesrepublik Deutschland anwenden könnte. Einen Schutz dagegen hat die Bundesrepublik

8 Am 18. Januar 1968 legten die beiden Ko-Präsidenten und Leiter der amerikanischen bzw. sowjetischen Delegation bei der Konferenz der 18-Mächte-Abrüstungskommission, Foster und Roschtschin, einen gemeinsamen Entwurf für ein Nichtverbreitungsabkommen vor. Vgl. dazu Dok. 21. 
Deutschland als Mitglied der NATO jedoch nur im Falle militärischer effektiver Anwendung von Kernwaffen, nicht gegen ihre Verwendung als Druckmittel.

Die Bundesregierung ist daher über die in vorstehendem Abschnitt II. 1) genannten Gründe hinaus an einer Verpflichtung der Sowjetunion interessiert, auf die Drohung mit (nuklearer) Gewalt zu verzichten.

Ein weiteres sich aus dem NV-Vertrag ergebendes Problem, das in dem Antwort-Entwurf ebenfalls noch nicht berücksichtigt ist, liegt in der Frage des "direkten oder indirekten Zugangs zu atomaren Waffen“. Die Sowjets haben einen deutschen Verzicht auf diesen „Zugang“ gefordert (vgl. oben Abschnitt II. 3a), gleichzeitig aber erklärt, daß dieser Punkt fortgelassen werden könne, falls die Bundesrepublik Deutschland sich dem NV-Vertrag anschließen würde. Es ist fraglich, $o b^{9}$ die Sowjets ihre alte Forderung wegen des „Zugangs“ durch den Beitritt zum NV-Vertrag als erfüllt anzusehen bereit sind. Jedoch ${ }^{10}$ muß angenommen werden, daß die sowjetische Regierung die Artikel I und II des NV-Vertrags ${ }^{11}$, die sie bereits als unveränderlich ansieht, uns gegenüber im Sinne ihrer alten Forderung (kein direkter oder indirekter Zugang zu Kernwaffen) extensiv auslegt. Sie fühlt sich hieran durch die amerikanischen Interpretationen ${ }^{12}$, die eine solche Auslegungsmöglichkeit einschränken sollten, offensichtlich nicht gehindert.

Es wäre daher denkbar, in die Antwort eine Klarstellung in dem Sinne aufzunehmen, daß die Bundesregierung die sowjetischen Alternativvorschläge so versteht, daß mit einer Unterzeichnung des NV-Vertrages (in der gegenwärtigen Fassung der Art. I und II) die sowjetische Forderung nach einem deutschen Verzicht auf „direkten oder indirekten Zugang“ zu Kernwaffen erfüllt ist, und daß die Sowjets nach einer deutschen Unterschrift unter den NV-Vertrag keine weiteren Forderungen gegen die Bundesrepublik Deutschland auf dem Gebiet der Kernwaffen mehr erheben.

Es wurde jedoch davon abgesehen, diese Frage schon in der ersten Antwort der Bundesregierung anzuschneiden, da dies zu einer deutsch-sowjetischen Diskussion über ein Thema geführt hätte, das zur Zeit auch Gegenstand ameri-

9 Die Wörter „Es ist fraglich, ob“ wurden von Ministerialdirektor Ruete handschriftlich eingefügt. Dafür wurde gestrichen: „Da“.

10 Dieses Wort wurde von Ministerialdirektor Ruete handschriftlich eingefügt.

11 Artikel I des amerikanisch-sowjetischen Entwurfs vom 18. Januar 1968 für ein Nichtverbreitungsabkommen: „Each nuclear-weapon State Party to this Treaty undertakes not to transfer to any recipient whatsoever nuclear weapons or other nuclear explosive devices or control over such weapons or explosive devices directly, or indirectly; and not in any way to assist, encourage, or induce any non-nuclear-weapon State to manufacture or otherwise acquire nuclear weapons or other nuclear explosive devices, or control over such weapons or explosive devices." Vgl. DOCUMENTS ON Disarmament 1968, S. 2. Für den deutschen Wortlaut vgl. Europa-ArChIV 1968, D 82.

Artikel II des amerikanisch-sowjetischen Entwurfs vom 18. Januar 1968 für ein Nichtverbreitungsabkommen: „Each non-nuclear-weapon State Party to this Treaty undertakes not to receive the transfer from any transferor whatsoever of nuclear weapons or other nuclear explosive devices or of control over such weapons or explosive devices directly, or indirectly; not to manufacture or otherwise acquire nuclear weapons or other nuclear explosive devices; and not to seek or receive any assistance in the manufacture of nuclear weapons or other nuclear explosive devices. $\mathrm{Vgl}$. DOCUMENTS ON DISARMAMENT 1968, S. 2 f. Für den deutschen Wortlaut vgl. EuROPa-ARCHIV 1968, D 82 .

$12 \mathrm{Zu}$ den amerikanischen Interpretationen für ein Nichtverbreitungsabkommen vgl. Dok. 104, Anm. 8. 
kanisch-sowjetischer Gespräche ist. Unsere Position ist besser, wenn die Amerikaner in ihren Interpretationen und im Rahmen der NATO klarstellen, daß die gegenwärtige Stellung der Bundesrepublik Deutschland auf nuklearem Gebiet mit dem NV-Vertrag voll vereinbar ist.

5) Gewaltverzicht gegenüber den Mitgliedstaaten des Warschauer Paktes (auBer „DDR“)

Wie bereits ausgeführt (vgl. oben Abschnitt II.3c), verlangen die Sowjets den gleichzeitigen Austausch ähnlicher Gewaltverzichtserklärungen mit allen Mitgliedern des Warschauer Paktes. Nach sowjetischer Mitteilung sind sämtliche uns bisher übermittelten Memoranden bis ins einzelne mit ihren Verbündeten abgestimmt worden. Ob dies tatsächlich zutrifft, und ob die Regierungen dieser Staaten zu echten bilateralen Verhandlungen mit uns (d.h. ohne Vorbedingungen) bereit sind, läßt sich nicht übersehen. Gomułka jedenfalls hat solche Gespräche in seiner Allensteiner Rede bereits abgelehnt. ${ }^{13}$ Es kann nicht in unserem Interesse liegen, gleichzeitig mit sieben Partnern über den Austausch von Gewaltverzichtserklärungen zu verhandeln oder uns einem Vorschlag gegenübergestellt zu sehen, der Einfachheit halber in einer gemeinsamen Konferenz die Fragen zu klären. Ebenso wenig wäre es aber angezeigt, uns bei den Gesprächen über die Grundsätze eines Gewaltverzichts bereits soweit festzulegen, daß die Ausgestaltung der übrigen bilateralen Erklärungen über den Gewaltverzicht präjudiziert und wir der Möglichkeit beraubt würden, je nach der Besonderheit des einzelnen bilateralen Verhältnisses zu differenzieren. Es ist auch nicht sicher, ob und in welchem Umfang die Sowjets alle Mitglieder des Warschauer Paktes konsultiert haben. Da wir vor allem an bilateralen Gesprächen interessiert sind, sollten wir die Souveränität der anderen Oststaaten unterstreichen und die Sowjets nicht von vornherein als deren gemeinsamen Sprecher akzeptieren. Dies ist auch im Hinblick auf eine spätere Veröffentlichung und auf unser Verhältnis zu den einzelnen Staaten (Rumänien!) zweckmäßig.

Wir sollten daher zwar bereit sein, mit der Sowjetregierung bei dem Gespräch über den deutsch-sowjetischen Gewaltverzicht auch gewisse allgemeine Grundsätze eines Gewaltverzichts zu erörtern. Dabei sollte aber von vornherein klargestellt werden, daß sowohl die Bundesregierung wie die anderen Mitglieder des Warschauer Paktes frei sein müssen, die einzelnen bilateralen Erklärungen über den Gewaltverzicht nach ihren Vorstellungen auszugestalten.

Wenn diesen Überlegungen gefolgt wird, sollte der Antwort-Entwurf noch einmal überarbeitet werden (Änderungen werden in der Einleitung des letzten Absatzes auf Seite $4^{14}$ und in Absatz 2 auf Seite $5^{15}$ erforderlich sein; auch wä-

13 Am 28. Oktober 1967 wies der Erste Sekretär des ZK der Polnischen Vereinigten Arbeiterpartei in einer Rede den von Bundesminister Brandt vorgeschlagenen Austausch von Gewaltverzichtserklärungen zurück: „Wir beabsichtigen nicht, die revisionistische und revanchistische Politik Bonns zu legalisieren." Vgl. den Artikel "Heftige Polemik aus Warschau“; FrankfurTer AlLgemeine ZeiTUNG, Nr. 252 vom 30 . Oktober 1967, S. 4.

14 Für den Neuformulierungsvorschlag des Ministerialdirigenten Sahm und die endgültige Formulierung der Einleitung des Absatzes in der Fassung des Aide-mémoires, die dem sowjetischen Botschafter Zarapkin am 9. April 1968 übergeben wurde, vgl. Dok. 39, Anm. 16.

15 Für den Neuformulierungsvorschlag des Ministerialdirigenten Sahm vgl. Dok. 39, Anm. 19. 
re auf Seite 9 in Ziffer 4 der letzte Satz zu streichen ${ }^{16}$ ). Es wäre auch zu erwägen, schon jetzt von uns aus bilaterale Kontakte mit den Regierungen der osteuropäischen Staaten (insbesondere Rumänien) zu suchen, um uns nicht dem Vorwurf auszusetzen, wir verhandelten über sie betreffende Fragen hinter ihrem Rücken mit den Sowjets.

6) Gewaltverzicht gegenüber der „DDR“

Aus sämtlichen sowjetischen schriftlichen und mündlichen Äußerungen geht hervor, daß der Austausch von Gewaltverzichtserklärungen zwischen uns und der „DDR" ein wichtiger, vielleicht der wichtigste Punkt für die Sowjets ist. Sie erhoffen sich dabei einen Fortschritt bei ihren Bemühungen um Anerkennung oder auf dem Wege zur Anerkennung der „DDR“. Auch wir sind an einem Gewaltverzicht zwischen uns und der „DDR“ interessiert (vgl. Brief des Bundeskanzlers an Stoph ${ }^{17}$; s. oben Abschnitt I. 3).

Für ein Eingehen auf die Forderung auf Gewaltverzicht mit der „DDR“ bieten sich folgende Möglichkeiten an:

i) Bereitschaft zu Verhandlungen mit der „DDR“

Damit könnte zunächst ein Aufschub der Angelegenheit erreicht werden, da die Verhandlungen mit der „DDR“ ebenso wie mit den osteuropäischen Staaten erst eingeleitet zu werden brauchen, nachdem erkennbar geworden ist, daß ein Übereinkommen mit der Sowjetunion in Aussicht steht.

Es ist aber auch nicht auszuschließen, daß die Sowjets von uns die unverzügliche Aufnahme von Verhandlungen mit der „DDR“ fordern. Wir kämen dann in die gleiche Lage wie nachstehend zu ii) dargestellt.

ii) Sofortiges Angebot an die „DDR“

Ein solches Angebot könnte in Fortsetzung des Briefwechsels des Bundeskanzlers mit Stoph, gegebenenfalls in Verbindung mit Vorschlägen für die gleichzeitige Regelung des friedlichen Nebeneinander, gemacht werden. Dieser Weg wäre zwar im Zuge unserer Entspannungspolitik gegenüber der Zone nützlich, würde aber andererseits Ulbricht die Möglichkeit geben, durch sofortige Ablehnung jeder für uns tragbaren Formulierung oder durch unakzeptable Forderungen, die wir ablehnen müßten, das deutsch-sowjetische Gespräch zu stören oder gar zum Abbruch zu bringen. Da aber die Beziehungen zur Sowjetunion jedenfalls in der gegenwärtigen Phase - Priorität gegenüber den innerdeutschen Angelegenheiten genießen sollten, empfiehlt es sich nicht, Ulbricht diese Möglichkeit in die Hand zu spielen.

iii) Einbeziehung in die deutsch-sowjetischen Gespräche

Es ist daher vorzuziehen, die Frage des Gewaltverzichts gegenüber der Zone in die deutsch-sowjetischen Gespräche einzubeziehen, wozu das bisherige Verhalten Zarapkins ausreichende Grundlage bietet. Wir könnten unsere Bereitschaft andeuten, mit der Sowjetunion als der für Deutschland als Ganzes verantwortlichen Macht und als der Führungsmacht im Osten die Grundzüge ei-

16 Für die vorgeschlagene Streichung des Ministerialdirigenten Sahm und die endgültige Formulierung des Satzes in der Fassung des Aide-mémoires, die dem sowjetischen Botschafter Zarapkin am 9. April 1968 übergeben wurde, vgl. Dok. 39, Anm. 37.

17 Zum Schreiben des Bundeskanzlers Kiesinger vom 28. September 1967 an den Vorsitzenden des Ministerrats der DDR vgl. Dok. 6, Anm. 7. 
nes derartigen Gewaltverzichts zu erörtern, ebenso wie die Sowjetunion offensichtlich daran interessiert ist, mit uns über andere Fragen zu sprechen, an denen in erster Linie andere Staaten interessiert sind (Oder-Neiße-Linie, Münchener Abkommen). Die Verhandlungen mit der Zone blieben dann einer späteren Zeit überlassen. Auch bleiben wir frei, jederzeit eine eigene Initiative gegenüber der Zone zu ergreifen, wenn wir es für angebracht halten sollten.

In diesem Sinne ist der die „DDR“ betreffende Abschnitt im letzten Absatz auf Seite 4 des Antwort-Entwurfs formuliert worden ${ }^{18}$.

III. Weiteres Verfahren

1) Es wird gebeten, Entscheidungen über die vorstehend genannten Fragen herbeizuführen:

[Zu] II. 1):

- Hinweis auf spezifische deutsche Sicherheitsinteressen. ${ }^{19}$

Zu II. 3):

- Eingehen auf die von den Sowjets mit dem Gewaltverzicht verbundenen Fragen;

- Gewaltverzicht notwendig, wenn keine Einigung über diese Fragen erzielt wird. ${ }^{20}$

$\mathrm{Zu} \mathrm{II.4):}$

- Gewaltverzicht notwendig, da im NV-Vertrag kein Schutz gegen nukleare Drohung;

- Keine Erwähnung des Verhältnisses zwischen „Verzicht auf Zugang zu nuklearen Waffen" und Inhalt NV-Vertrag. ${ }^{21}$

Zu II.5):

- Unterscheidung der bilateralen Verhandlungen mit osteuropäischen Staaten;

- Vorsichtige Kontakte mit Rumänien und anderen osteuropäischen Staaten. ${ }^{22}$

$\mathrm{Zu}$ II. 6):

- Bereitschaft, mit Sowjets über Gewaltverzicht zwischen uns und „DDR“ zu sprechen. 23

2) Alsdann wird das Auswärtige Amt unter Berücksichtigung der Entscheidungen ${ }^{24}$ zu dem Entwurf eine neue Fassung herstellen.

3) Nach Genehmigung der endgültigen Fassung Unterrichtung der Drei Mächte. ${ }^{25}$

18 Vgl. dazu Dok. 39, besonders Anm. 17.

19 Dazu handschriftliche Bemerkung des Bundesministers Brandt: „Ja, aber nicht zu ausführlich."

20 Zum Passus „Eingehen auf ... erzielt wird“ handschriftliche Bemerkung des Bundesministers Brandt: „Ja.“

21 Zum Passus „Gewaltverzicht notwendig ... Inhalt NV-Vertrag“ handschriftliche Bemerkung des Bundesministers Brandt: "Ja.

22 Zum Passus „Unterscheidung der ... anderen osteuropäischen Staaten“ handschriftliche Bemerkung des Bundesministers Brandt: „Ja.“

23 Dazu handschriftliche Bemerkung des Bundesministers Brandt: „Ja.“

$24 \mathrm{Zu}$ den Beratungen der Bundesregierung am 6. März 1968 in Berlin (West) vgl. Dok. 88.

25 Am 1. April 1968 legte Ministerialdirektor Ruete einen ,entsprechend den Wünschen des Bundeskanzleramts“ geänderten Entwurf des Aide-mémoires der Bundesregierung über den Gewaltverzicht für eine Besprechung mit Bundesminister Wehner vor, in dem die "noch im Stadium der Konsultation befindlichen Stellen" gekennzeichnet waren. Für den Wortlaut des Entwurfs vom 31. März 1968 und den Begleitvermerk von Ruete vgl. VS-Bd. 4432 (II A 4); B 150, Aktenkopien 1968. 
4) Übergabe an Botschafter Zarapkin. ${ }^{26}$

Hiermit über den Herrn Staatssekretär ${ }^{27}$ dem Herrn Bundesminister ${ }^{28}$ vorgelegt.

Ruete

VS-Bd. 4432 (II A 4)

\section{Aufzeichnung des Ministerialdirektors Ruete}

II A 5-82.60/0-94.22-381 $1 / 68$ VS-vertraulich

4. März 1968

Betr.: Einbeziehung Berlins in ein deutsch-rumänisches Kulturabkommen; hier: Unterredung mit Botschafter Oancea am 22. ${ }^{1}$ und 29.2.1968

Anl.: $5^{2}$

I. Botschafter Oancea und ich erörterten am 22. und 29. Februar 1968 eingehend die mit der Anwendung des Kulturabkommens auf Berlin zusammenhängenden Fragen. Diese Gespräche sind erst jetzt zustandegekommen ${ }^{3}$, da Herr Oancea auf meinen Hinweis von Anfang Dezember 1967, wir seien gesprächsbereit, nicht vorher zu einem Termin bereit war. Wir vereinbarten, den Gedankenaustausch am 7. März hier fortzusetzen. Seiner Anregung, den Gedankenaustausch in Bukarest fortzusetzen, hielt ich entgegen, es sei sachdienlicher, daß diejenigen die Erörterungen fortführten, die sich in die Problematik bereits eingearbeitet hätten.

Botschafter Oancea wollte seiner Regierung erst nach der nächsten Begegnung berichten.

26 Zur Übergabe des Aide-mémoires an den sowjetischen Botschafter Zarapkin am 9. April 1968 vgl. Dok. 121.

27 Georg Ferdinand Duckwitz.

28 Hat Bundesminister Brandt vorgelegen.

1 Am 22. Februar 1968 notierte Ministerialdirektor Ruete über das Gespräch mit dem rumänischen Botschafter: „Oancea präzisierte seine anfänglichen Darlegungen: Seine Regierung sei bereit, die bei der Aufnahme der diplomatischen Beziehungen geübte Prozedur auch für den Abschluß des Kulturabkommens zu verwenden. Öffentliche Erklärungen seien allerdings nicht mehr nötig. Sie sei damit einverstanden, daß wir zum strikt internen Gebrauch eine unsere prinzipiellen Auffassungen enthaltende Aufzeichnung im Verlauf der Kulturverhandlungen verlesen. Die rumänische Seite werde in ,freundschaftlicher und nicht engagierender Weise ${ }^{\imath}$ sagen, wie sie die grundsätzliche Frage beurteile. Die freundschaftliche Reaktion könne, wenn wir es seiner Regierung erleichterten, auch im Schweigen bestehen. Bei Indiskretionen behalte sich seine Regierung vor, entsprechend zu antworten." Vgl. VS-Bd. 4315 (II A 5); B 150, Aktenkopien 1968.

2 Dem Vorgang beigefügt. Für Auszüge vgl. Anm. 5-9.

3 Zum letzten Gespräch des Ministerialdirektors Ruete mit dem rumänischen Botschafter Oancea über den Abschluß eines Kulturabkommens am 27. November $1967 \mathrm{vgl}$. AAPD 1967, III, Dok. 403. 
1) Wir einigten uns ad referendum auf folgendes Verfahren:

- Das bei der Aufnahme der diplomatischen Beziehungen geübte Verfahren ${ }^{4}$ soll auch für das Verfahren bei dem Abschluß des Kulturabkommens als Anhalt dienen.

- Die rumänische Seite sieht sich zu einer gemeinsamen Erklärung über Berlin außerstande. Sie zeigt aber dafür Verständnis, wenn wir aus „interner Notwendigkeit" ein Protokoll vorbereiten und im Verlauf der Kulturverhandlungen verlesen wollen, das unsere grundsätzlichen Auffassungen wiedergibt. Die rumänische Seite wird daraufhin „freundschaftlich und unverbindlich" die Haltung ihrer Regierung hinsichtlich Berlins darlegen.

- Auf öffentliche Erklärungen nach Abschluß eines Kulturabkommens soll verzichtet werden. Bei Indiskretionen behält sich die rumänische Regierung vor, entsprechend zu antworten. (Die Notwendigkeit, auf Presseanfragen in Deutschland antworten zu müssen, muß noch mit den Rumänen behandelt werden.)

2) Ferner besprachen wir:

- Die rumänische Regierung ist auf dieser Grundlage bereit, bald Kulturverhandlungen zwischen Experten hier oder in Bukarest aufzunehmen. Ich begrüßte die rumänische Verhandlungsbereitschaft, bestand aber darauf, daß wir Verhandlungen erst aufnehmen könnten, wenn die Kernfrage der Einbeziehung Berlins durch vorbereitete Texte befriedigend beantwortet sei. Wir könnten uns ein Scheitern der Verhandlungen nicht leisten.

- Botschafter Oancea schien persönlich zu dem Gentleman-Agreement bereit, daß der deutsche Delegationsleiter bei Beginn der Expertenverhandlungen den von uns zu vereinbarenden Wortlaut des deutschen Protokolls dem rumänischen Delegationsleiter verliest. Eine schriftliche Vorvereinbarung über das Ergebnis unserer Berlin-Erörterungen lehnte er ab.

- Wir stimmten darin überein, daß, sollte ein beiderseits annehmbarer Wortlaut für das Protokoll gefunden werden, auf dieser Grundlage auch der Abschluß anderer Abkommen denkbar ist.

3) Erhebliche Schwierigkeiten ergaben sich bei der Erörterung des Wortlauts des deutschen Protokolls. Ich übergab am 22. einen Entwurf gemäß Anlage 1) ${ }^{5}$.

Herr Oancea stie $\beta$ sich in einer „persönlichen ersten Reaktion“ an unserer Formulierung „der bisherigen Praxis“. Bisher hätten wir kein Kulturabkommen

4 Anläßlich der Aufnahme diplomatischer Beziehungen mit Rumänien am 31. Januar 1967 gab Bundeskanzler Kiesinger die Erklärung ab, dieser Schritt bedeute keine Änderung des „deutschen Rechtsstandpunktes, daß die Bundesregierung allein berechtigt und verpflichtet ist, für das ganze deutsche Volk zu sprechen“. Vgl. BuLlETIN 1967, S. 81.

Die rumänische Regierung bekräftigte ihrerseits, daß sie den Standpunkt aufrechterhalte, „daß es zwei deutsche Staaten gibt und es sich hier um eine der grundlegenden Realitäten handelt, die Europa als Folge des Zweiten Weltkriegs und der weiteren Entwicklung der Dinge auferlegt wurden“. Vgl. Europa-ARCHIV 1967, D 116.

5 Dem Vorgang beigefügt. Im Entwurf vom 22. Februar 1968 einer Erklärung der Bundesregierung wurde ausgeführt: „Die Regierung der Bundesrepublik Deutschland geht davon aus, daß die bisherige Praxis in den Beziehungen zwischen der Bundesrepublik Deutschland und der Sozialistischen Republik Rumänien auch für das Kulturabkommen gilt. Sie geht ferner davon aus, daß die diesbezüglichen Rechtsstandpunkte beider Seiten durch den Abschluß des Kulturabkommens nicht berührt werden." Vgl. VS-Bd. 4315 (II A 5); B 150, Aktenkopien 1968. 
abgeschlossen: „Die Beziehungen im ökonomischen Bereich haben allgemein den einen, im kulturellen einen anderen Charakter". In den Kulturbeziehungen bestehe bereits eine Praxis hinsichtlich Berlins. Seine Regierung gedenke, diese nicht einzuschränken. Dies müsse uns genügen.

Ich übergab sodann am 29. einen zweiten Entwurf gemäß Anlage 2) ${ }^{6}$. Dieser lehnt sich im 1. Absatz an den diesbezüglichen Wortlaut der Erklärung an, die wir anläßlich der Aufnahme der diplomatischen Beziehungen im Januar 1967 verlesen hatten. (Es erschien zweckmäßig, an das damals benutzte Verfahren anzuknüpfen, das die Rumänen als Anhalt bezeichnet hatten.) Im 2. Absatz wollten wir im Lichte der Ausführungen, die Herr Oancea am 22. hinsichtlich der "Praxis“ gemacht hatte, die „Praxis“ auf die zwischen uns schon bestehenden „vertraglichen“ Beziehungen abstellen. Der 3. Absatz berücksichtigt rumänische Argumente.

Herr Oancea bezeichnete auch diesen Entwurf als „keineswegs annehmbar“ und als eine Lösung erschwerend. Ihm erscheine es unwahrscheinlich, daß der rumänische Delegationsleiter die Verlesung eines solchen Protokolls schweigend hinnehmen könne. Als persönliche Auffassung, die allerdings die ihm bekannte Haltung seiner Regierung berücksichtige, improvisierte er eine eigene Fassung des deutschen Protokolls gemäß Anlage 3$)^{7}$.

II. Aus Herrn Oanceas Ausführungen ging deutlich hervor, daß die Rumänen sich scheuen, die bisher unmittelbar mit Berlin unterhaltenen Kulturbeziehungen künftig in irgendeiner Form in den Rahmen des Kulturabkommens zu stellen.

Ich ließ in beiden Gesprächen keinen Zweifel darüber aufkommen, daß wir verpflichtet sind, auch die bereits mit Berlin bestehenden Kulturbeziehungen in das Abkommen einzubeziehen. Bei der Verwirklichung des Kulturabkommens seien wir gern bereit, Rücksicht auf die rumänische Interessenlage zu nehmen und von spektakulären Demonstrationen abzusehen, die im Kulturbereich die Verbindung zwischen Berlin und dem Bund unterstreichen sollen.

III. Ich schlage vor, in dem nächsten Gespräch, wie mit Herrn Oancea vereinbart, einen dritten Entwurf des deutschen Protokolls gemäß Anlagen 4) ${ }^{8}$

6 Dem Vorgang beigefugt. Im Entwurf vom 29. Februar 1968 einer Erklärung der Bundesregierung wurde erläutert: „Vor Aufnahme der Verhandlungen über den Abschluß eines Kulturabkommens haben beide Regierungen eingehend die mit der Anwendung des Kulturabkommens auf Berlin zusammenhängenden Fragen erörtert. Die deutsche Seite hat dabei bekräftigt, daß die Regierung der Bundesrepublik Deutschland davon ausgehe, daß die bisherige Praxis in den vertraglichen Beziehungen zwischen der Bundesrepublik Deutschland und der Sozialistischen Republik Rumänien auch für das Kulturabkommen gilt. Beide Seiten haben ihre prinzipiellen Auffassungen über die weitere Entwicklung der kulturellen und wissenschaftlichen Beziehungen $z$ wischen den beiden Staaten zum Ausdruck gebracht." Vgl. VS-Bd. 4315 (II A 5); B 150, Aktenkopien 1968.

7 Dem Vorgang beigefügt. Im Entwurf vom 29. Februar 1968 einer Erklärung der Bundesregierung, die auf Formulierungen des rumänischen Botschafters Oancea zurückging, wurde ausgeführt: „Beide Regierungen haben vor Aufnahme der Verhandlungen über den Abschluß eines Kulturabkommens über kulturelle und wissenschaftliche Beziehungen gesprochen. Dabei haben beide Seiten ihre prinzipiellen Auffassungen dargelegt, nach denen sie ihre kulturellen und wissenschaftlichen Beziehungen entwickeln wollen, und zwar auf der Grundlage der Praxis, die in diesem Bereich herbeigeführt worden ist." Vgl. VS-Bd. 4315 (II A 5); B 150, Aktenkopien 1968.

8 Dem Vorgang beigefügt. In der ersten Fassung eines Entwurfs vom 7. März 1968 einer Erklärung der Bundesregierung wurde festgestellt: ${ }_{n}$ Vor Aufnahme der Verhandlungen über den Abschluß eines Kulturabkommens haben beide Seiten ihre prinzipiellen Auffassungen über die weitere 
und 5$)^{9}$ zu übergeben. Die Aussicht, daß er diesen, einen äußersten deutschen Kompromiß darstellenden Text hinnimmt, ist nicht sehr groß.

Es stellen sich danach für die Fortsetzung des Gesprächs folgende Alternativen:

1) Wir beharren auf dem von uns vorgeschlagenen Wortlaut und nehmen eine rumänische Gegenerklärung hin. Es bleibt abzuwarten, ob die rumänische Gegenerklärung, deren Wortlaut uns vorher mitgeteilt werden müßte, für uns annehmbar sein wird.

2) Wir verzichten zunächst auf weitere Gespräche über den Abschluß eines deutsch-rumänischen Kulturabkommens. Damit würden wir der bewährten Praxis in den deutsch-rumänischen Beziehungen folgen, bekannt strittige Probleme auszuklammern, um die sonst befriedigende Zusammenarbeit nicht unnötig zu belasten. Der Abschluß eines Kulturabkommens ist nicht von einseitigem Vorteil für uns, wir könnten also warten. Andererseits verzichten wir damit zugleich auf eine demonstrative Anreicherung des deutsch-rumänischen Verhältnisses, an der auch uns gelegen ist. Ferner verlieren wir das präjudizierende Vorbild eines Kulturabkommens aus der Hand, auf das wir uns im Verhältnis zu anderen Staaten berufen könnten.

3) Wir verzichten auf die Formalisierung der Einbeziehung Berlins in ein Kulturabkommen und verhandeln - entsprechend einer Anregung von Abteilung IV - in Expertengesprächen über die Bildung eines Gemischten Ausschusses, die in einem formlosen Protokoll vereinbart werden könnten. Diese Minimallösung hätte den Vorteil, daß die Bekanntgabe des Ergebnisses die Öffentlichkeit auf zufriedenstellende Verhandlungen schließen läßt. Die rumänische Seite müßte allerdings zumindest damit einverstanden sein, eine Erläuterung über die Einbeziehung Berlins in dieses Programm in der Form hinzunehmen, da $\beta$ „ein formeller Vertrag, der die Einbeziehung Berlins erforderlich mache, nicht geschlossen worden sei, die vereinbarte Leitlinie des zukünftigen Handelns im Lichte der bisherigen Praxis jedoch die Gewähr für die Nichtdiskriminierung Berlins gäbe“.

\section{Fortsetzung Fußnote von Seite 305}

Entwicklung der kuiturellen und wissenschaftlichen Beziehungen zwischen den beiden Staaten zum Ausdruck gebracht. Dabei hat die deutsche Seite bekräftigt, daß die Regierung der Bundesrepublik Deutschland davon ausgeht, daß die bisherige Praxis in den vertraglichen Beziehungen zwischen den beiden Staaten auch für das Kulturabkommen gelten soll. In gleicher Weise soll künftig auch im Hinblick auf alle anderen Verträge verfahren werden, die zwischen den beiden Staaten abgeschlossen werden, ohne daß es über diesen Punkt einer besonderen Vereinbarung bedürfte. Die rumänische Seite unterstrich in diesem Zusammenhang, daß diese Praxis nichts an ihrem grundsätzlichen Rechtsstandpunkt ändert, wonach Berlin kein Teil der Bundesrepublik Deutschland sei." Vgl. VS-Bd. 4315 (II A 5); B 150, Aktenkopien 1968.

9 Dem Vorgang beigefügt. In der zweiten Fassung eines Entwurfs vom 7. März 1968 einer Erklärung der Bundesregierung wurde ausgeführt: „Vor Aufnahme der Verhandlungen über den Abschluß eines Kulturabkommens haben beide Seiten ihre prinzipiellen Auffassungen über die weitere Entwicklung der kulturellen und wissenschaftlichen Beziehungen zwischen den beiden Staaten zum Ausdruck gebracht. Dabei bestand Einverständnis darüber, daß in Zukunft Berlin nicht unterschiedlich behandelt werden soll. In gleicher Weise soll künftig auch im Hinblick auf alle anderen Verträge verfahren werden, die zwischen den beiden Staaten abgeschlossen werden, ohne $\mathrm{da} ß$ es über diesen Punkt einer besonderen Vereinbarung im Einzelfall bedürfte. Die rumänische Seite unterstrich in diesem Zusammenhang, daß diese Praxis nichts an ihrem grundsätzlichen Rechtsstandpunkt ändert, wonach Berlin kein Teil der Bundesrepublik Deutschland sei.“Vgl. VSBd. 4315 (II A 5); B 150, Aktenkopien 1968. 
4) Wir schließen ein Kulturabkommen unter Verzicht auf die Berlin-Klausel ab. Diese Lösung wäre rechtlich möglich, politisch jedoch vermutlich schwer durchsetzbar.

IV. Ich schlage vor, daß wir uns in dem nächsten Gespräch ${ }^{10}$ zunächst, wie unter Ziffer III, 1 skizziert, weiterhin um den Wortlaut einer pragmatischen, für die Rumänen annehmbaren deutschen Erklärung bemühen und gegebenenfalls über eine für uns annehmbare rumänische Gegenerklärung verhandeln. Wenn, was ich nicht ausschließe, der rumänische Widerstand unverändert andauert, schlage ich vor, den Rumänen, unter Hinweis auf den in Ziffer III, 2 enthaltenen Gedankengang, die Unterbrechung unserer Bemühungen um ein Kulturabkommen nahezulegen. Wir könnten dann nach Ablauf einer Bedenkzeit einen Ausweg auf der Grundlage des unter Ziffer III, 3 geschilderten Verfahrens finden.

Hiermit über den Herrn Staatssekretär ${ }^{11}$ dem Herrn Minister mit der Bitte um Entscheidung vorzulegen.

Abteilung V hat mitgezeichnet.

Ruete

VS-Bd. 4315 (II A 5)

10 Am 7. März 1968 übergab Ministerialdirektor Ruete dem rumänischen Botschafter Entwürfe für eine Erklärung der Bundesregierung beim Abschluß eines Kulturabkommens. Oancea erklärte, „alsbald Stellungnahme seiner Regierung zu den Entwürfen "einzuholen. Vgl. die Aufzeichnung von Ruete vom 15. März 1968; VS-Bd. 4315 (II A 5); B 150, Aktenkopien 1968.

Am 15. März 1968 bat Ruete die Botschaft in Bukarest, im rumänischen Außenministerium zu erklären, daß die Bundesregierung in den Gesprächen mit Botschafter Oancea "bis zum äußersten "gegangen sei: „Der Verhandlungsverlauf habe jedoch nur sehr geringe Fortschritte hinsichtlich der erforderlichen Einigung über die Einbeziehung Berlins ergeben. Wir müßten jedoch Gewißheit darüber haben, daß Berlin nach Abschluß des Kulturabkommens nicht unterschiedlich behandelt werde. Daher hofften wir, daß einer unserer Entwürfe für die rumänische Regierung annehmbar sei." Vgl. den Drahterlaß Nr. 159; VS-Bd. 4315 (II A 5); B 150, Aktenkopien 1968.

11 Hat Staatssekretär Duckwitz am 6. März 1968 vorgelegen, der auf einer Begleitnotiz für Staatssekretär Lahr handschriftlich vermerkte: „Ich finde den Abschluß eines Kultur-Abkommens politisch so wichtig, daß ich glaube, wir sollten eine Erklärung der rumänischen Regierung ruhig akzeptieren, die Berlin nicht expressis verbis ausschließt.“ Vgl. VS-Bd. 4315 (II A 5); B 150, Aktenkopien 1968.

Hat Lahr am 7. März 1968 vorgelegen, der handschriftlich für Ministerialdirektor Ruete vermerkte: „Nach heutiger Morgenbespr[echung] ist Vorlage an den H[errn] Min[ister] m. E. verfrüht." Hat Ruete erneut am 7. März vorgelegen, der für Referat II A 5 handschriftlich dazu vermerkte: "Ja. ${ }^{*}$ 


\section{1}

\section{Botschafter Schnippenkötter, z.Z. Genf, an das Auswärtige Amt}

\author{
Z B 6-1-11447/67 geheim \\ Fernschreiben Nr. 156 \\ Citissime
}

Aufgabe: 4. März 1968, 14.50 Uhr

Ankunft: 4. März 1968, 15.48 Uhr

1) Habe heute weisungsgemäß mit dem sowjetischen Delegationschef, Botschafter Roschtschin, ein einstündiges Gespräch geführt. Auf sowjetischer Seite nahmen Schustow und Tulinow teil, in meiner Begleitung befanden sich VLR I Lahusen und LR I Diesel.

2) Roschtschin sagte über das voraussichtliche weitere Verfahren auf der Genfer Konferenz, daß er die Vorlage des von der VN-Vollversammlung angeforderten vollständigen Berichts termingerecht zum 15. März noch immer für wahrscheinlich halte. ${ }^{1}$ Mit einer Verlängerung der Konferenz über diesen Termin hinaus rechne er nicht. Der vollständige Bericht werde die Vorgänge auf der Genfer Konferenz im Jahre 1968 und für einen Teil des Jahres 1967 dekken. Im einzelnen sei der Bericht von den beiden Co-Chairmen ${ }^{2}$ allerdings noch nicht vorbereitet worden. Es werde wie üblich ein reiner "factual report" werden, der keine Zustimmung der ENDC zu den vorliegenden Entwürfen zum Ausdruck bringen, sondern nur den Gang der Verhandlungen schildern werde. Sämtliche relevanten Dokumente würden beigefügt werden.

Der Vertragsentwurf ${ }^{3}$ werde möglicherweise noch in einigen kleineren Punkten geändert werden (small modifications); er habe aber noch keine entsprechende Instruktion aus Moskau (Roschtschin äußerte sich hierzu wesentlich vorsichtiger, als es der allgemeinen Erwartung in Genf entsprochen hätte).

3) Die VN-Vollversammlung wird nach Ansicht Roschtschins wahrscheinlich kurz nach Ostern wieder zusammentreten. ${ }^{4}$ Wie sie mit dem Bericht verfahren werde, lasse sich nicht vorhersehen. Er hoffe, daß sie die Annahme des Vertrags empfehlen werde. Eine Rückverweisung des Vertragsentwurfs an die Genfer Konferenz hält Roschtschin für wenig wahrscheinlich. Er hoffe, daß der NV-Vertrag vor der Genfer Konferenz der Nichtkernwaffenmächte Ende August dieses Jahres ${ }^{5}$ unterzeichnet wird; damit würde die Aufgabe dieser Konferenz „erleichtert".

4) Roschtschin forderte mich auf, die deutsche Auffassung zum NV-Vertragsentwurf darzulegen. Ich antwortete, ich würde mich in meinen Darlegungen auf die Gestaltung des Vertragstextes beschränken und Punkte, die neben dem

\footnotetext{
1 Zum Bericht der Konferenz der 18-Mächte-Abrüstungskommission, die am 14. März 1968 endete, vgl. Dok. 82, Anm. 3.

2 William C. Foster (USA) und Alexej Alexandrowitsch Roschtschin (UdSSR).

3 Für den Wortlaut des amerikanisch-sowjetischen Entwurfs vom 18. Januar 1968 für ein Nichtverbreitungsabkommen vgl. DocumenTS on DisARMAMENT 1968, S. 1-6. Für den deutschen Wortlaut vgl. EUROPA-ARCHIV 1968, D 81-85.

4 Die XXII. UNO-Generalversammlung nahm am 24. April 1968 ihre Tätigkeit wieder auf.

5 Die Konferenz der Nichtnuklearstaaten fand vom 29. August bis 28 . September 1968 statt.
} 
Vertrag der Regelung bedürften, jetzt nicht ansprechen. Zum Vertragstext legte ich die deutschen Wünsche weisungsgemäß (anhand des genehmigten Sprechzettels $^{6}$ und des Infex Nr. 1 vom 21. Februar ${ }^{7}$ ) wie folgt dar:

- verstärkte Verbindung mit Abrüstung;

- verbesserte Anpassungsfähigkeit des Vertrages in den Verfahrensbestimmungen, wobei nicht jede Verfahrensbestimmung (Rücktritt, Revision, Überprüfung, Vertragsdauer, Inkrafttreten) flexibler gestaltet, die Verfahrensbestimmungen insgesamt aber eine größere Anpassungsfähigkeit vorsehen müßten;

- Ausschluß von Druck, Drohung und Erpressung im Vertragstext als Regulativ für die Beziehungen zwischen Kernwaffenmächten und Nichtkernwaffenmächten nach Abschluß des Vertrages (code of ethics).

5) Roschtschin zeigte sich interessiert. Er wollte wissen, ob die möglicherweise in Aussicht stehenden „kleinen Änderungen“ unseren Wünschen voll Rechnung trügen. Ich vermied eine direkte Beantwortung dieser Frage, stellte aber fest, daß sie in Richtung unserer Wünsche gehen würden.

6) $\mathrm{Zu}$ unserem Wunsch nach Ausschlu $\beta^{8}$ von Druck, Drohung und Erpressung erklärte Roschtschin, er verstehe ihn als einen Aspekt der Sicherheitsgarantien. Die Ausgangslagen der hieran interessierten Nichtkernwaffenstaaten seien sehr verschieden. Deswegen lasse sich eine generelle Lösung im Vertrag selbst schwer finden. Man sei daher auf den Ausweg einer Regelung „parallel“ zum NV-Vertrag verfallen. Diese Regelung (Sicherheitsratsresolution nebst einseitigen Erklärungen der Kernwaffenmächte) werde de facto, nicht juristisch mit dem Vertrag verbunden werden. "We can assure you that the connection will be quite real." Diese Regelung werde allen Teilnehmern am NV-Vertrag ohne Unterschied zugute kommen, wie Roschtschin auf wiederholte Frage bestätigte..$^{9}$

6 Für die Aufzeichnung des Ministerialdirektors Ruete vom 27. Februar 1968 vgl. VS-Bd. 4349 (II B 1); B 150, Aktenkopien 1968.

Auf einem Begleitvermerk notierte Bundesminister Brandt am 29. Februar 1968 handschriftlich für Staatssekretär Duckwitz: „Über Anlage eines etwaigen Gesprächs zwischen Schnippenkötter und Roschtschin sollte im Lichte der Eindrücke entschieden werden, mit denen Sie aus Wlashinglton zurückkommen. Bei den Interpretationen gilt es jedenfalls sehr aufzupassen." Vgl. VS-Bd. 4349 (II B 1); B 150, Aktenkopien 1968.

7 Ministerialdirektor Ruete übermittelte den Auslandsvertretungen einen „Informations- und Sprachregelungserla $\beta^{\star}$ : „Die Bundesregierung glaubt, daß der Vertragsentwurf noch weiter verbessert werden sollte, damit er weltweite Zustimmung erfahren kann. Sie vertritt dabei keine Sonderinteressen, sondern befindet sich in Übereinstimmung mit anderen Nichtkernwaffenstaaten. Insbesondere sollte die Verbindung des Vertrages mit Abrüstung (Artikel VI und Präambel des Entwurfs), vor allem auch mit nuklearer Abrüstung, verstärkt werden. Die Verfahrensvorschriften sollten flexibler gestaltet werden, damit der Vertrag leichter an künftige Entwicklungen angepaßt werden kann. Er würde dadurch an Stabilität gewinnen. Im Interesse der Ausgewogenheit der Vertragsverpflichtungen zwischen Kernwaffen- und Nichtkernwaffenstaaten sollte die Präambel eine Klausel zum Ausschluß von politischem Druck, politischer Drohung und politischer Erpressung mit Kernwaffen gegenüber Nichtkernwaffenstaaten enthalten. Die nichtnuklearen Vertragsstaaten könnten sich insoweit dann zu ihren Gunsten auf den Vertrag berufen. “ Für den am 20. Februar 1968 konzipierten Runderlaß vgl. VS-Bd. 10080 (Ministerbüro); B 150, Aktenkopien 1968.

8 Korrigiert aus: ${ }_{n}$ Abschluß“.

9 Am 4. März 1968 teilte Botschafter Schnippenkötter, z.Z. Genf, ergänzend mit, er könne nicht beurteilen, ob der Leiter der sowjetischen Delegation bei der Konferenz der 18-Mächte-Abrüstungskommission, Roschtschin, sich des Problems bewußt gewesen sei, „daß hier ein Verzicht auf sowjetische Siegerrechte in Frage steht, wie sie in Art. 53 und 107 der VN-Charta (Zulässigkeit von 
7) Weisungsgemäß wies ich mit einem Satz auf die Bedeutung hin, die wir den westlichen Interpretationen der Artikel I, II und III ${ }^{10}$ beimessen müßten, da diese Vertragsbestimmungen einen verständlicherweise nicht ganz eindeutig formulierten Kompromiß darstellten.

8) Das Klima des Gesprächs war erfreulich und sachlich. Roschtschin enthielt sich jeden Vorwurfs, jeder Polemik. Jeder Anflug eines Druckes auf uns fehlte. Roschtschins verständnisvolles Interesse an der Darlegung unseres Standpunktes und sein sachliches Eingehen darauf sind bemerkenswert. Das oft von verbündeter Seite verwandte Argument, Wünsche an den Vertrag hätten stets dann eine geringere Aussicht auf sowjetische Annahmebereitschaft, wenn sie den „German label" trügen, fand in dem Gesprächsverlauf keine Bestätigung. Unsere von Roschtschin offensichtlich als maßvoll empfundenen Positionen, die sich außerdem mit den Wünschen anderer ENDC-Mitglieder decken, hätten ihm allerdings eine andere Haltung auch sehr erschwert.

[gez.] Schnippenkötter

VS-Bd. 4349 (II B 1)

Fortsetzung Fußnote von Seite 309

Zwangsmaßnahmen gegen Besiegte außerhalb der Maschinerie der Vereinten Nationen) Ausdruck gefunden haben“. Weiter führte er aus: „Da Roschtschin unseren Wunsch nach Ausschluß von Druck, Drohung und Erpressung in dem Rahmen der VN-Sicherheitsgarantien einordnet, kommen wir an der Frage nicht vorbei, ob die in der VN-Charta noch verankerte Minderstellung des Besiegten einer Befriedigung unseres Wunsches nach Art der Erklärung Roschtschins entgegensteht oder nicht.“ Vgl. den Drahtbericht Nr. 158; VS-Bd. 4349 (II B 1); B 150, Aktenkopien 1968.

10 Für den Wortlaut der Artikel I und II des amerikanisch-sowjetischen Entwurfs vom 18. Januar 1968 für ein Nichtverbreitungsabkommen vgl. Dok. 79, Anm. 11.

Zu Artikel III (Kontrollartikel) des amerikanisch-sowjetischen Entwurfs vom 18. Januar 1968 für ein Nichtverbreitungsabkommen vgl. Dok. 3, Anm. 20. 


\section{Botschafter Schnippenkötter, z.Z. Genf, an das Auswärtige Amt}

\author{
Z B 6-1-11449/68 geheim \\ Fernschreiben Nr. 157 \\ Citissime
}

Aufgabe: 4. März 1968, 15.45 Uhr

Ankunft: 4. März 1968, 16.48 Uhr

1) Ich war um $10 \mathrm{Uhr}$ bei Roschtschin ${ }^{1}$ und um 12 Uhr bei Foster. Zwischen 11 und 12 war Foster bei Roschtschin. Das Gespräch zwischen den beiden Ko-Präsidenten betraf den Sicherheitsrat-Resolutionsentwurf über Sicherheitsgarantien (assurances) ${ }^{2}$ und den Entwurf für eine diesbezügliche Erklärung der $\mathrm{Nu}$ klearmächte. Roschtschin hat Foster über die Unterredung mit mir nichts gesagt, während ich Foster über den Verlauf meines Gesprächs mit Roschtschin unterrichtete. Foster bedankte sich dafür (ich hatte ihn vorsorglich über das bevorstehende Gespräch unterrichten lassen; mein Besuch bei ihm war auch im Hinblick darauf vereinbart worden).

2) Foster hatte gehofft, die Russen würden sich damit einverstanden erklären, daß der Genfer Konferenz morgen der Ko-Präsidenten-Entwurf der Sicherheitsrats-Resolution über Sicherheitsgarantien unterbreitet wird. Roschtschin aber hatte noch keine Instruktionen dazu.

Nach Fosters Darstellung ist der Stand folgender: Die Ko-Präsidenten sind sich einig, die Frage des Nichtgebrauchs von Kernwaffen (non-use) aus der Resolution und den Erklärungen herauszulassen. Der einzig offene Punkt soll ein Ersatz für die von den Amerikanern abgelehnte und von Roschtschin schon wieder fallengelassene „punishment-Formel“ sein (d.i. die Frage der Sanktionen gegen eine Nuklearwaffenmacht, die Kernwaffen anwendet oder damit droht). Der Resolutionsentwurf soll Bestandteil des Genfer Abschlußberichts ${ }^{3}$ werden.

1 Zum Gespräch mit dem Leiter der sowjetischen Delegation bei der Konferenz der 18-MächteAbrüstungskommission in Genf vgl. Dok. 81.

2 Im gemeinsam von Großbritannien, der UdSSR und den USA erarbeiteten Entwurf vom 7. März 1968 für eine Resolution wurde ausgeführt: Der UNO-Sicherheitsrat „1) erkennt an, daß eine Aggression mit Kernwaffen oder die Androhung einer solchen Aggression gegen einen kernwaffenlosen Staat eine Lage schaffen würde, in welcher der Sicherheitsrat und vor allem die Kernwaffenstaaten, die in ihm ständige Mitglieder sind, im Einklang mit ihren Verpflichtungen aus der Charta der Vereinten Nationen unverzüglich handeln müßten; 2) begrüßt die von bestimmten Staaten erklärte Absicht, daß sie jedem kernwaffenlosen Staat, der Partei des Vertrags über die Nichtverbreitung von Kernwaffen ist und das Opfer eines Aggressionsaktes oder das Objekt einer Aggressionsdrohung mit Kernwaffen wird, im Einklang mit der Charta unverzüglich Hilfe leisten oder solche Hilfeleistung unterstützen werden". Vgl. EuROPA-ARCHN 1968, D 215.

3 Im Bericht der Konferenz der 18-Mächte-Abrüstungskommission vom 14. März 1968 an die UNO wurde erläutert: "In view of the urgency of concluding a treaty to prevent the proliferation of nuclear weapons $[. .$.$] the Committee has continued to give its primary attention to the negotiation$ of this treaty." Vgl. DocumentS On Disarmament 1968, S. $192 \mathrm{f}$. Für den deutschen Wortlaut vgl. Europa-ARChIV 1968, D $216 \mathrm{f}$.

Dem Bericht wurden u. a. der amerikanisch-sowjetische Entwurf vom 11. März 1968 für ein Nichtverbreitungsabkommen und der gemeinsam von Großbritannien, der UdSSR und den USA erarbeitete Entwurf vom 7. März 1968 für eine Resolution des UNO-Sicherheitsrats beigefügt. 
Die Verbindung der „Resolution“ und der „Erklärungen“ mit dem NV-Vertrag bestehe aus nichts anderem, so sagte Foster, als der Einverleibung in den Abschlußbericht und der Beschränkung auf die Teilnehmer am NV-Vertrage.

3) Foster betonte, daß die „Resolution“ und die „Erklärungen“ im VN-Rahmen gesehen werden müßten, also unter Wahrung des Rechts auf individuelle und kollektive Selbstverteidigung (Artikel 51 VN-Charta ${ }^{4}$ ). Ich deutete daraufhin die Problematik an, die sich aus Artikel 53 und 107 ergeben könnte (d.i. der Vorbehalt der Gewaltanwendung gegen die Besiegten des Zweiten Weltkriegs außerhalb der Friedenssicherungsmaßnahmen des Sicherheitsrats). Amerikaner gaben zu erkennen, daß sie sich der Fragestellung wohl bewußt seien, daß sich das Problem für den westlichen Teil der Welt nicht mehr stellt. Ich erwähnte nicht das Problem, ob die Sowjetunion in diesem Zusammenhang bereit ist, die Siegerrechte aus Artikel 53 und 107 aufzugeben. Auf meinen gesonderten Bericht zu diesem Komplex darf ich Bezug nehmen. ${ }^{5}$

4) Foster ist sehr skeptisch, ob Moskau sich noch in dieser Woche über die erwarteten Verbesserungen des Vertragsentwurfs äußern wird.

Die Gründe für den Aufschub der Entscheidung Moskaus sind wie in früheren ähnlich gelagerten Situationen schwer zu durchschauen. Foster neigt wiederum dazu, dies der Schwerfälligkeit des sowjetischen Apparats zuzuschreiben. Er hält es auch für möglich, daß die Russen ihre Äußerung bis zuletzt zurückhalten, um jede weitere Diskussion in Genf abzuschneiden. Weitere denkbare Gründe blieben unerörtert.

5) Nach Fosters Auffassung soll der Abschlußbericht die Verhandlungsgeschichte seit 1965 widerspiegeln (in diesem Punkte nicht ganz übereinstimmend mit dem, was Roschtschin mir gesagt hat). Die Dokumentation soll die Erklärungen der Konferenzmitglieder und die als Konferenzdokumente zirkulierten Memoranden der Nichtkonferenzmitglieder (Schweiz ${ }^{6}$ und Spanien ${ }^{7}$ )

4 Artikel 51 der UNO-Charta: „Nothing in the present Charter shall impair the inherent right of individual or collective self-defense if an armed attack occurs against a Member of the United Nations, until the Security Council has taken the measures necessary to maintain international peace and security. Measures taken by Members in the exercise of this right of self-defense shall be immediately reported to the Security Council and shall not in any way affect the authority and responsibility of the Security Council under the present Charter to take at any time such action as it deems necessary in order to maintain or restore international peace and security." Vgl. CHARTER OF THE UNITED NATIONS, S. 686.

5 Zum Drahtbericht Nr. 158 vom 4. März 1968 vgl. Dok. 81, Anm. 9.

6 Im Memorandum vom 17. November 1967 führte die schweizerische Regierung aus: „The Treaty will establish a lasting juridical discrimination between States according to whether they possess nuclear weapons or not. To consent to this would represent for the non-nuclear-weapon States a heavy sacrifice which is inconceivable unless something is given in return. Since their security is what the arms race chiefly endangers, some progress should be made in limiting this." Vgl. DOCUMENTS ON DISARMAMENT 1967, S. 573.

7 Im Memorandum vom 8. Februar 1968 führte die spanische Regierung aus: „Lastly, a feature which the Spanish Government misses in the text submitted to the Conference of the EighteenNation Disarmament Committee on 18 January last is any measure relating to the guarantees which must be given to non-nuclear countries by signatories possessing nuclear weapons, first that they shall not be attacked or threatened with attack by nuclear weapons, and secondly that, if a nuclear Power or party to the treaty attacks or threatens to attack a non-nuclear signatory, all nuclear parties to the treaty shall react appropriately." Vgl. DOCUMENTS ON DISARMAMENT 1968, S. 41. 
enthalten. Da das Memorandum der $\mathrm{DDR}^{8}$ lediglich mit Begleitbrief der sowjetischen Delegation verteilt worden ist und deswegen nach amerikanischer Auffassung nicht Konferenzdokument wurde, halten die Amerikaner eine Aufnahme in die Dokumentation für nicht gerechtfertigt.

6) Fosters ließ keinen Zweifel, daß die VN-Diskussion in der zweiten Aprilhälfte beginnen ${ }^{9}$ und mit einer Resolution abschließen soll, die Auflage des Vertrages zur Unterzeichnung fordert. Änderungen in New York schließt Foster nicht aus; sie sollen aber „entmutigt“ werden.

[gez.] Schnippenkötter

VS-Bd. 4349 (II B 1)

83

\section{Gespräch des Staatssekretärs Duckwitz mit dem türkischen Botschafter Gökmen}

Herr Staatssekretär Duckwitz empfing am 5. März 1968 um 11 Uhr den türkischen Botschafter, Herrn Gökmen, zu einer vierzigminütigen Unterredung.

Der Herr Staatssekretär sprach zunächst sein Bedauern darüber aus, daß er Botschafter Gökmen erst nach seiner Washington-Reise ${ }^{2}$ empfangen könne.

Er habe ihm nun mitzuteilen, daß die Bundesregierung nach langem Abwarten und Hinausschieben - in der Hoffnung auf eine Konsolidierung der Lage auf Zypern - das Agrément für den neuen zyprischen Botschafter in der Bundesre-

8 Am 10. Oktober 1967 verlas der Leiter der sowjetischen Delegation bei der Konferenz der 18 Mächte-Abrüstungskommission, Roschtschin, in Genf eine Erklärung der Regierung der DDR. Er führte $u$.a. aus: „Es ist kein Zufall, daß die Regierung der westdeutschen Bundesrepublik alle möglichen Einwände gegen einen Vertrag über die Nichtweiterverbreitung von Kernwaffen erhebt. Diese Einwände sollen die eigentlichen Hintergründe des Widerstandes der westdeutschen Regierung gegen den Abschluß eines solchen Vertrages verdecken. Kernwaffen werden von der westdeutschen Bundesregierung als geeignete Instrumente angesehen, um ihre auf die Veränderung des Status quo gerichteten Bestrebungen zu verwirklichen. Mit Atomwaffen als ,einer militärischen Potenz' soll der aggressiven Alleinvertretungsanmaßung und dem Streben nach Änderung der Grenzen in Europa Nachdruck verliehen werden." Vgl. DzD V/1, S. 1791.

9 Die XXII. UNO-Generalversammlung nahm am 24. April 1968 ihre Tätigkeit wieder auf.

1 Die Gesprächsaufzeichnung wurde von Dolmetscherin Bouverat am 6. März 1968 gefertigt. Hat Staatssekretär Duckwitz am 6. März 1968 vorgelegen, der die Weiterleitung an Bundesminister Brandt, z.Z. Berlin (West), verfügte: „Botschafter Gökmen ist bekannt, daß unser Beschluß der Erteilung des Agréments an den zyprischen Botschafter in Bonn unabänderlich ist. Es kommt ihm meines Erachtens nur noch darauf an, seiner Regierung mitteilen zu können, daß er den Standpunkt seiner Regierung dem Herrn Bundesminister mitgeteilt hat." Vgl. den Drahterlaß vom 6. März 1968; VS-Bd. 2721 (I A 4); B 150, Aktenkopien 1968.

Hat Botschafter z. b. V. Böker vorgelegen.

Hat Vortragendem Legationsrat Hansen vorgelegen.

2 Staatssekretär Duckwitz beendete am 29. Februar 1968 seinen Besuch in den USA. 
publik $^{3}$ erteilt habe. Aus Rücksicht gegenüber der Türkei habe man von deutscher Seite Erzbischof Makarios sogar gebeten, nicht um das Agrément nachzusuchen. In der Zwischenzeit habe dieser jedoch zu verstehen gegeben, daß er nicht bereit sei, länger zu warten. Bekanntlich befinde sich die Bundesregierung in bezug auf Zypern in einer etwas heiklen Lage wegen der möglichen Aufwertung der dortigen Vertretung der DDR. Die Bundesregierung bitte daher die türkische Regierung um Verständnis für ihre Entscheidung.

Botschafter Gökmen erwiderte, es stehe seiner Regierung natürlich nicht zu, Akte einer anderen souveränen Regierung zu kritisieren. Im Falle der Ernennung des zyprischen Botschafters in der Bundesrepublik lägen die Dinge aber ganz anders: In der Behandlung dieser Angelegenheit durch Makarios sei von Anfang an ein sehr genaues, logisches System zu erkennen gewesen. Völkerrechtlich sei die Lage wie folgt: Durch die Verfassung der Republik Zypern seien die beiden Bevölkerungsgruppen (communautés) - die griechische und die türkische - miteinander assoziiert worden. Trotz des Verfassungsbruchs von Ende 1963, durch den die türkische Bevölkerungsgruppe in die Enge getrieben und von der griechischen Gruppe getrennt worden sei, sei die Verfassung immer noch gültig. Danach habe der türkische Vizepräsident ein Vetorecht bei der Ernennung von zyprischen Missionschefs im Ausland sowie bei diplomatischen Vertretern auf der Insel. ${ }^{4}$ Infolgedessen würde die DDR niemals „Legalität erlangen können" ohne die Zustimmung des Vizepräsidenten.

Die türkische Regierung sei der Bundesregierung sehr dankbar für die Verzögerung der Entscheidung und für den Schritt, den sie bei Makarios unternommen habe. $\operatorname{Er}$ (Botschafter Gökmen) habe gehofft, daß die genannte Frage von deutscher Seite auch weiterhin als nicht dringend betrachtet würde und daß man sie in aller Ruhe würde durchdiskutieren können. Seine Regierung sei sehr unangenehm überrascht gewesen, insbesondere was den Zeitpunkt der deutschen Entscheidung betreffe, der weder für die Türkei noch für die türkische Bevölkerungsgruppe auf Zypern glücklich sei: nach den jüngsten Wahlen ${ }^{5}$ habe man auf türkischer Seite die weitere Entwicklung abwarten und entsprechende Verhandlungen in die Wege leiten wollen. Durch den Entschluß der Bundesregierung sei aber das Prestige von Makarios übermäßig gestärkt worden, und zwar zum Schaden der türkischen Zyprer.

$\operatorname{Er}$ (Botschafter Gökmen) sei persönlich etwas enttäuscht darüber, daß ihm vor der deutschen Entscheidung nicht - wie formell zugesagt ${ }^{6}$ - Gelegenheit gebo-

3 Christodoulos C. Fissentzides.

4 In Artikel 50 der Verfassung der Republik Zypern vom 16. August 1960 wurde u.a. ausgeführt: "The President and the Vice-President of the Republic, separately or conjointly, shall have the right of final veto on any law or decision of the House of Representatives or any part thereof concerning a) foreign affairs [...]. For the purposes of this sub-paragraph, foreign affairs includes the recognition of States, the establishment of diplomatic and consular relations with other countries and the interruption of such relations. The grant of acceptance to diplomatic representatives and of exequatur to consular representatives. The assignment of diplomatic representatives and of consular representatives, already in the diplomatic service, to posts abroad and the entrusting of functions abroad to special envoys already in the diplomatic service." Vgl. CONSTITUTIONS: CYPRUS, S. $22 \mathrm{f}$.

5 In den Wahlen vom 25. Februar 1968 wurde Präsident Makarios in seinem Amt bestätigt.

6 Die Wörter „wie formell zugesagt" wurden von Botschafter z.b.V. Böker hervorgehoben. Dazu handschriftliche Bemerkung: „Stimmt nicht!“ 
ten worden sei, den Standpunkt seiner Regierung nochmals dem BundesauBenminister oder dem Herrn Staatssekretär darzulegen. Dabei hätte er gerne mit seinen deutschen Gesprächspartnern geprüft, wie man der öffentlichen Meinung in der Türkei und auf Zypern die deutsche Entscheidung erläutern könnte. Im übrigen sei es erfreulich, daß die Bundesregierung sich - wie auch im Falle der arabischen Länder - nicht durch Drohungen und Erpressungsversuche in bezug auf eine mögliche Anerkennung der DDR habe einschüchtern lassen. Drohungen sollten bei der Bildung eines Urteils kein zu großes Gewicht haben. Wenn die Bundesregierung die getroffene Entscheidung, wie ihm gesagt worden sei, für das "geringere Übel" halte, so handle es sich hierbei um ein Werturteil, über das man nicht streiten wolle; vom türkischen Standpunkt aus betrachtet, treffe dies aber auf lange Sicht nicht zu.

Der türkische Botschafter wiederholte zusammenfassend, daß seine Regierung Bedenken hinsichtlich des „timing“7 der deutschen Entscheidung habe, durch die der Anschein erweckt werde, als ob die Bundesregierung alle bisherigen „illegalen und verfassungswidrigen Akte“ von Erzbischof Makarios legalisiere. Der neue deutsche Botschafter auf Zypern ${ }^{8}$ habe sich im übrigen Makarios gegenüber bereits als nachgiebig erwiesen, da er alle Kontakte zu dem türkischen Vizepräsidenten ${ }^{9}$ eingestellt ${ }^{10}$ habe. Dies alles sei Anlaß zu um so größerer Enttäuschung für sein Land, als dieses nicht nur traditionell, sondern auch gefühlsmäßig mit Deutschland befreundet sei, wobei es sich nicht nur um eine „Schönwetter-Freundschaft" handle.

Der Herr Staatssekretär dankte für die Ausführungen des Botschafters, die einige für ihn neue Gesichtspunkte enthielten. Leider sei die Lage auf Zypern noch völlig ungeklärt: jede Partei behaupte etwas anderes, so daß es für AuBenstehende schwierig sei, „sich auf diesem Glatteis zu bewegen, ohne auszurutschen." Von deutscher Seite habe man dieser Situation lange Rechnung getragen und sich um ein Verständnis des türkischen Standpunktes bemüht. Als praktischer Beweis hierfür möge u. a. das Telegramm des Bundesaußenministers an seinen türkischen Kollegen während der Zypernkrise gelten, in dem eine deutsche Vermittlerrolle angeboten worden sei. ${ }^{11} \mathrm{Er}$ (der Herr Staatssekretär) bedaure, daß der Zeitpunkt der deutschen Entscheidung zu Mißverständnissen Anlaß gegeben habe; es handle sich aber wirklich nur um einen unglücklichen Zufall. Zu der Bemerkung des Botschafters in bezug auf „das

7 Dieses Wort wurde vom Vortragenden Legationsrat Hansen hervorgehoben. Dazu handschriftliche Bemerkung: ,Also war mehr das T[iming].“"

8 Alexander Török.

9 Fazil Küçük.

10 Dieses Wort wurde von Botschafter z.b.V. Böker hervorgehoben. Dazu Fragezeichen und handschriftliche Bemerkung: "Nicht aufgenommen!“

11 Am 23. November 1967 bat Ministerialdirigent Frank die Botschaft in Ankara, dem türkischen Außenminister Çaglayangil eine Mitteilung des Bundesministers Brandt zu übergeben: „In dieser für den Frieden im östlichen Mittelmeer und den Weltfrieden entscheidenden Stunde richten sich die Blicke des befreundeten deutschen Volkes auf Ihre Regierung und das türkische Volk. Die Freundschaft unserer beiden Völker gibt mir die Gewißheit, daß Sie meinen Appell als ein Zeichen aufrichtiger und uneigennütziger Friedensliebe aufnehmen. Ich wäre Ihnen dankbar, wenn Sie Ihrer Regierung davon Mitteilung machen würden und darf Sie bitten, von meiner Bereitschaft zu vermittelnden Diensten Gebrauch zu machen, wenn Sie dies für sinnvoll halten." Vgl. den Drahterlaß Nr. 4380; VS-Bd. 2440 (I A 4); B 150, Aktenkopien 1967.

Vgl. dazu auch AAPD 1967, III, Dok. 411. 
geringere Übel“" sei zu sagen, daß er selbst es nicht so formuliert haben würde. Die Erfahrung in den Beziehungen nicht nur der Völker, sondern auch der Menschen zueinander bewirke aber, daß man immer davon ausgehe, bei Freunden ein größeres Verständnis zu finden und daher Freunden mehr zumuten zu können als Menschen ${ }^{12}$, mit denen man nicht so eng befreundet sei. Er hoffe, daß der Botschafter die Lage der Bundesregierung verstanden habe und seiner Regierung entsprechend berichten werde.

Botschafter Gökmen sagte dies zu und wies nochmals darauf hin, daß bedauerlicherweise die öffentliche Meinung in der Türkei in bezug auf die Zypernfrage besonders empfindlich sei, was in den meisten Fällen ein gesundes und gelassenes Urteil unmöglich mache. Persönlich finde er es auch bedauerlich, daß es ihm offensichtlich nicht gelungen sei, bei der Bundesregierung genügend Verständnis für den türkischen Standpunkt zu erwecken. ${ }^{13}$

Der Herr Staatssekretär zerstreute diese Bedenken und versprach, daß er die Bundesregierung nochmals auf die Schwierigkeit des Problems und seine emotionelle Bedeutung hinweisen werde. ${ }^{14}$ Als Zeichen für die freundschaftliche Verbundenheit der Bundesrepublik zu der Türkei möge der Hinweis darauf genügen, daß der Herr Bundeskanzler ${ }^{15}$ beschlossen habe, der Türkei einen Besuch abzustatten. ${ }^{16}$

VS-Bd. 2721 (I A 4)

12 An dieser Stelle wurde von Botschafter z.b. V. Böker gestrichen: „gegenüber“.

13 Am 6. März 1968 berichtete Botschafter Schwarzmann aus einem Gespräch mit dem türkischen Botschafter, daß Gökmen „die formelle Weisung von seinem Minister erhalten habe, wegen der Erteilung des Agréments für den neuen zyprischen Botschafter den Minister des Auswärtigen aufzusuchen. Auf meinen Hinweis, daß er doch gestern Gelegenheit gehabt habe, beim Stellvertreter des Herrn Ministers, Herrn Staatssekretär Duckwitz, sein Anliegen vorzubringen, erwiderte er, daß er sehr dankbar gewesen sei, von dem Herrn Staatssekretär empfangen worden zu sein; er glaube jedoch, daß in diesem kritischen Augenblick - gerade wegen der freundschaftlichen Beziehungen zwischen Deutschland und der Türkei - es bei ihm zu Hause nicht verstanden werden würde, wenn er keine Gelegenheit gehabt hätte, den Herrn Minister persönlich - auch wenn es sich nur um einige Minuten handelt - zu sehen."Vgl. VS-Bd. 2721 (I A 4); B 150, Aktenkopien 1968.

14 Mit Schreiben vom 27. März 1968 teilte Staatssekretär Duckwitz dem türkischen Botschafter Gökmen folgendes mit: „Am 8. und 13. März 1968 haben Sie dem Herrn Bundesminister des Auswärtigen das Anliegen Ihrer Regierung vorgetragen, den Amtsantritt des neuen Botschafters von Zypern in Bonn noch einige Zeit hinauszuschieben. Auf diese Weise sollte die Möglichkeit offengehalten werden, die schwebenden Verfassungsfragen auf Zypern einer Klärung näher zu bringen. Ich darf Ihnen jetzt mitteilen, daß es uns gelungen ist, die zyprische Regierung von der Zweckmäßigkeit eines solchen Aufschubs zu überzeugen. Demnach ist nicht vor Anfang Juni mit dem Eintreffen von Herrn Botschafter Fissentzides zu rechnen." Vgl. VS-Bd. 2721 (I A 4); B 150, Aktenkopien 1968.

Der zyprische Botschafter Fissentzides überreichte Bundespräsident Lübke am 21. Juni 1968 sein Beglaubigungsschreiben. Vgl. dazu BULLETIN 1968, S. 694.

15 An dieser Stelle wurde von Botschafter z.b.V. Böker gestrichen: „trotz Absage aller anderen Auslandsreisen für dieses Jahr“.

16 Am 4. März 1968 notierte Botschafter Schwarzmann, daß er ${ }_{\text {am }}$ heutigen Tage den türkischen Botschafter davon in Kenntnis gesetzt habe, daß der Herr Bundeskanzler der Einladung des türkischen Ministerpräsidenten Demirel, die Türkei in der Zeit vom 9. bis 12. September 1968 aufzusuchen, gern Folge leisten wird“. Vgl. VS-Bd. 2721 (I A 4); B 150, Aktenkopien 1968.

Zum Gespräch des Bundeskanzlers Kiesinger mit Demirel vgl. Dok. 285. 


\section{Aufzeichnung des Staatssekretärs Duckwitz}

\section{St.S. 470 I/68 VS-vertraulich}

5. März 1968

Betr.: Gespräch mit dem Abteilungsleiter für Europa im Department of State, John M. Leddy, am 28. Februar 1968'; außerdem anwesend: Alfred Puhan, Herbert S. Malin (DeutschlandAbteilung), Gesandter v. Lilienfeld

Leddy eröffnete das Gespräch mit dem Hinweis, daß die sich zuspitzende Lage in Vietnam ${ }^{2}$ und die amerikanischen Zahlungsbilanzsorgen erneuten Druck von Senator Mansfield und anderen im Kongreß in Richtung zusätzlicher Truppenabzüge von Europa zur Folge haben werde. Er bedauerte, daß die vor einem Jahr vereinbarten Truppenreduktionen ${ }^{3}$ noch nicht durchgeführt worden seien, da Pressenachrichten hierüber den Druck etwas abfangen könnten. Ich entgegnete, daß die allgemeine Haltung in Europa unverändert dahin gehe, daß keine zusätzlichen amerikanischen Truppen abgezogen werden sollten, so lange dies vermieden werden könne. Leddy äußerte dann den Gedanken, ob man in Ostasien abgezogene britische Truppen zum Teil auf dem europäischen Kontinent stationieren könne. Dies könnte das Interesse Großbritanniens an Europa unterstreichen. Healey hätte dies vor einiger Zeit in einer Rede angedeutet. 4

Ich entgegnete, daß dieser Gedanke vielleicht von uns mit den Briten aufgegriffen werden sollte, um so mehr, als diese wahrscheinlich Schwierigkeiten haben würden, die Truppen in Großbritannien unterzubringen, und der Druck, sie zu demobilisieren, stark sein würde. Ich erwähnte dann den bevorstehenden Besuch der Delegation des Verteidigungsministeriums und teilte mit, daß unsere Planung für den Verteidigungshaushalt wahrscheinlich im April abgeschlossen werden würde.

Leddy meinte, daß die Sowjets zwar auf den Gedanken gegenseitiger Truppenreduzierungen in Europa so lange nicht eingehen würden, als der Krieg in Vietnam andauere. Trotzdem sollte dieser Gedanken in der Diskussion gehalten werden. Aus dem gleichen Grund hätten die USA bisher in der Diskussion der

1 Das Gespräch fand anläßlich des Besuchs des Staatssekretärs Duckwitz vom 26. bis 29. Februar 1968 in Washington statt.

2 Am 26. Februar 1968 erklärte dazu der ehemalige General Clay gegenüber Staatssekretär Duckwitz: „Im Augenblick liege die Initiative ausschließlich bei den Vietcong und den nordvietnamesischen Streitkräften. Eine Anderung der Lage könne wahrscheinlich nur dadurch erzielt werden, daß sich das amerikanische Oberkommando zu einem Einmarsch nach Nordvietnam entschließt. Da nach Ansicht der Amerikaner Nordvietnam von Truppen weitgehend entblößt sei, seien Erfolge in kürzester Zeit zu erwarten." Vgl. die Aufzeichnung vom 27. Februar 1968; VS-Bd. 479 (Büro Staatssekretär); B 150, Aktenkopien 1968.

$3 \mathrm{Zu}$ den am 27./28. April 1967 in London festgelegten Rückverlegungen amerikanischer und britischer Streitkräfte aus der Bundesrepublik zum 1. Januar 1968 vgl. AAPD 1967, I, Dok. 151.

4 Am 25. Januar 1968 erklärte der britische Verteidigungsminister vor dem Unterhaus: „As a consequence of our withdrawal we shall, despite the big cut in our expenditure, have available a bigger proportion of our defence resources for the defence of Europe than we have today“. Vgl. HANSARD, Bd. 757, Sp. $624 \mathrm{f}$. 
ABM-Frage keinen Erfolg gehabt. Er halte es jedoch nicht für ausgeschlossen, daß die Sowjets eines Tages den Weitergang der Rüstung auf beiden Seiten als unproduktiv betrachten könnten.

Zum NV-Vertrag erwähnte ich unsere drei noch unberücksichtigten Hauptpunkte $^{5}$ und wies auf die schwierige innenpolitische Situation im Hinblick auf den Vertrag hin. In diesem Zusammenhang erwähnte ich den bei Eugene Rostow angeschnittenen Gedanken einer Garantie-Erklärung des amerikanischen Präsidenten. ${ }^{6}$

Im Hinblick auf Berlin stimmte die amerikanische Seite mit meiner Beurteilung überein, daß man keine wirklichen Anzeichen für eine neue Berlin-Krise aus den kürzlichen sowjetischen Mitteilungen ${ }^{7}$ erkenne. Mr. Puhan meinte allerdings, daß es anläßlich der Tagung des Bundestages in Berlin vom 5 . bis 8. März $^{8}$ vielleicht doch zu Zwischenfällen kommen könnte. Offensichtlich versuchten die Sowjets, die verschiedenen Nuancen in der Haltung der drei Westmächte gegenüber Berlin zu Störmanövern zwischen diesen auszunutzen. Ich fragte, ob die Erklärung der Verschiedenartigkeit der russischen Mitteilung an Frankreich darin liegen könne, daß dieses nicht an der Potsdamer Konferen $z^{9}$ teilgenommen habe. Leddy bezweifelte dies und meinte, daß die Russen das besonders starke französische Interesse an einer Détente mit dem Osten auszubeuten versuchten. Er teilte dann mit, daß die Amerikaner mit dem deutschen Entwurf ${ }^{10}$ auf das sowjetische Berlin-Memorandum vom 6. Januar ${ }^{11}$ voll übereinstimmten. Dieser sei ausgezeichnet. Es sei in unserem und auch im westlichen Interesse wichtig, daß auch die Antwort der drei Westmächte auf den Brief von Abrassimow identisch ausfalle. ${ }^{12} \mathrm{Er}$ hoffe, daß Paris den von der französischen Botschaft in Bonn vorgelegten Entwurf billigen werde.

5 Vgl. dazu Dok. 65.

6 Zum Gespräch mit dem Staatssekretär im amerikanischen Außenministerium am 29. Februar 1968 in Washington vgl. Dok. 77.

Für den Entwurf vom 29. Februar 1968 der Bundesregierung für eine Garantieerklärung des Präsidenten Johnson vgl. Dok. 77, Anm. 8.

7 Am 14. Februar 1968 teilte der sowjetische Botschafter in Ost-Berlin, Abrassimow, den Botschaftern der Drei Mächte, McGhee (USA), Roberts (Großbritannien) und François Seydoux (Frankreich), mit, daß das „Ausmaß der ungesetzlichen Tätigkeit der deutschen Bundesrepublik in Westberlin systematisch erweitert [worden sei]. Die Regierung der deutschen Bundesrepublik hat es zur Praxis gemacht, regelmäßig sogenannte ,Parlamentswochen' durchzuführen, Tagungen von Fraktionen und Ausschüssen des Bundestages in Westberlin abzuhalten. "Ferner wurde gegen die Bundesregierung der Vorwurf erhoben, "Westberlin allmählich in ihre Kriegsvorbereitungen mit einzubeziehen, obwohl diese Versuche den besonderen Status Westberlins, der durch entsprechende interalliierte Abkommen festgelegt wurde, nicht ändern können." Vgl. DzD V/2, S. 237.

8 Vom 4. bis 8. März 1968 fand in Berlin (West) eine Parlamentarische Arbeitswoche des Bundestages statt.

9 Die Konferenz fand vom 17. Juli bis 2 . August 1945 statt.

10 Zum Memorandum der Bundesregierung vom 1. März 1968 vgl. Dok. 75.

11 Vgl. dazu Dok. 4, Anm. 3.

12 Am 3. März 1968 machten die Botschafter McGhee (USA), Roberts (Großbritannien) und François Seydoux (Frankreich) u. a. darauf aufmerksam, daß gemäß „Viermächteabkommen der besondere Status, auf den Sie sich in Ihrem Schreiben beziehen, nicht auf die Westsektoren beschränkt ist, sondern sich auf die gesamte Stadt Berlin erstreckt." Vgl. DzD V/2, S. 315. 
Leddy fragte dann nach unserer Deutung des Begriffs der „Rundherum-Verteidigung". ${ }^{13}$ Ich antwortete, daß wir dies mit den Franzosen aufgegriffen hätten. Verteidigungsminister Messmer stimme mit diesem Konzept überein, Couve jedoch nicht. Während des Besuches des Kanzlers in Paris ${ }^{14}$ habe de Gaulle die Vorstellung von General Ailleret bestätigt. In Deutschland sei dieser Begriff wenig in der Öffentlichkeit diskutiert worden.

Mr. Leddy fragte dann, was der Bundeskanzler in einer kürzlichen Rede mit dem Begriff eines „atlantischen Imperiums" ${ }^{15}$ gemeint habe. Gesandter von Lilienfeld erklärte hierzu, daß der Kanzler zwar eine volle Partnerschaft Europas mit den USA, jedoch keine beherrschende Rolle der USA über Europa wünsche.

Zum Schluß kam das Gespräch auf die Tschechoslowakei. Ich äußerte mich im großen ganzen zuversichtlich über die Entwicklungen unserer Beziehungen. Zunächst müsse das neue tschechische Regime jedoch seine Loyalität gegenüber Moskau unter Beweis stellen. Im großen ganzen sei die Reaktion der Dritten Welt auf unsere Aufnahme von diplomatischen Beziehungen mit Rumänien und Jugoslawien ${ }^{16}$ erfreulich gewesen.

Von amerikanischer Seite wurde dann noch die Frage der Abschaffung der TTDs $^{17}$ und der Rückgabe der Berliner Dokumentenzentrale ${ }^{18}$ an die Bundesrepublik angeschnitten. Ich sagte zu, beide Fragen nach meiner Rückkehr nach Bonn zu prüfen.

Hiermit dem Herrn Minister ${ }^{19}$ vorgelegt.

Duckwitz

VS-Bd. 479 (Büro Staatssekretär)

13 Zum Konzept der „Rundumverteidigung“ vgl. Dok. 43, Anm. 8.

14 Bundeskanzler Kiesinger hielt sich anläßlich der deutsch-französischen Konsultationsbesprechungen am 15./16. Februar 1968 in Paris auf. Vgl. dazu Dok. 59, Dok. 60 und Dok. 62.

15 Vgl. dazu Dok. 69.

16 Die diplomatischen Beziehungen mit Rumänien und Jugoslawien wurden am 31. Januar 1967 bzw. am 31. Januar 1968 aufgenommen.

17 Am 4. März 1968 teilte der amerikanische Gesandte Fessenden Ministerialdirektor Ruete dazu mit, daß im amerikanischen Außenministerium die Frage gestellt werde, ob es sinnvoll sei, das TTD-System weiter aufrechtzuerhaiten. Man habe im State Department das Gefühl, daß dieses System sich selbst überlebt habe. Es werde von den Zonenmachthabern für ihre eigenen Zwecke mißbraucht; auf der einen Seite griffen sie es heftig an, auf der anderen Seite benutzten sie es, um Auslandsreisen der Bevölkerung zu verhindern. Dies sei insbesondere bei älteren Menschen, anderen humanitären Fällen und Reisen von Geistlichen der Fall." Vgl. die Aufzeichnung von Ruete; VS-Bd. 8530 (Ministerbüro); B 150, Aktenkopien 1968.

18 Berlin Document Center.

19 Hat Bundesminister Brandt vorgelegen. 


\section{5}

\section{Hausbesprechung}

I B 2-82.00-91

5. März 1968 1

Betr.: Aktivierung der deutschen Lateinamerika-Politik

Am 5. März 1968 fand unter Vorsitz von Staatssekretär Duckwitz eine Besprechung über die Aktivierung der deutschen Lateinamerika-Politik statt, an der die aus der Anlage $1^{2}$ ersichtlichen Herren teilgenommen haben.

Staatssekretär Duckwitz eröffnete um 16.00 Uhr die Sitzung, begrüßte die Teilnehmer und verwies als Besprechungsgrundlage auf die Aufzeichnung der Abteilung I vom 9. August $1967^{3}$. Er schlug vor, zunächst den politischen Teil dieser Aufzeichnung (Abschnitt A) zu besprechen und erteilte Herrn Botschafter Böker das Wort.

Herr Böker erinnerte daran, daß der Anstoß zu den in der Aufzeichnung enthaltenen Vorschlägen von den Lateinamerikabesuchen der Staatssekretäre Prof. Carstens und Lahr im Jahre 1966 ausgegangen sei. ${ }^{4}$ Beide Herren seien stark beeindruckt gewesen von dem Deutschland in allen lateinamerikanischen Ländern entgegengebrachten good will, dem das Gefühl einer gewissen Vernachlässigung von deutscher Seite gegenüber gestanden habe. In der Tat sei ein politisches Interesse an Lateinamerika in Deutschland erst seit dem Auftreten Fidel Castros festzustellen, mit dem auch eine wachsende Verselbständigung Lateinamerikas gegenüber den Vereinigten Staaten verbunden sei.

1 Die Gesprächsaufzeichnung wurde von Legationsrat I. Klasse Leuteritz am 7. März 1968 gefertigt. Mit Begleitschreiben vom 29. März 1968 leitete Ministerialdirigent Caspari die Aufzeichnung über Staatssekretär Duckwitz an Bundesminister Brandt weiter. Vgl. Referat I B 2, Bd. 582.

Hat Duckwitz am 29. März 1968 vorgelegen.

Hat Brandt vorgelegen.

2 Dem Vorgang beigefügt. Neben Staatssekretär Duckwitz nahmen an der Hausbesprechung teil: Staatssekretär Lahr, Botschafter z.b.V. Böker, Ministerialdirektor Harkort, die Ministerialdirigenten Berger, Caspari, Lohmann und Overbeck, Botschafter Graf von Welczeck, die Vortragenden Legationsräte I. Klasse Arnold, Borchardt, Meyer-Lohse, Reufels, Ritzel und Röding, Vortragender Legationsrat Noebel, Legationsrat I. Klasse Leuteritz, Legationsrat Gehl sowie Legationssekretär Aurisch. Vgl. Referat I B 2, Bd. 582.

3 Ministerialdirigent Böker notierte zur „Aktivierung der deutschen Lateinamerika-Politik“: „Seit der Wiederaufnahme der diplomatischen Beziehungen mit den lateinamerikanischen Ländern in den Jahren 1952 und 1953 hat sich die Bundesregierung ständig bemüht, das große politische Kapital an Deutschfreundlichkeit, welches trotz der durch den Krieg bedingten Unterbrechung der Beziehungen in jenen Ländern noch vorhanden war, zu pflegen und zu erhalten. Die Bundesregierung hat sich ebenfalls bemüht, diesen Ländern bei der Überwindung ihrer wirtschaftlichen Schwierigkeiten im Rahmen der ihr gegebenen Möglichkeiten zu helfen (Schuldenkonsolidierung, Kapitalhilfe, Technische Hilfe). In der deutschen Öffentlichkeit wurde indessen die politische Bedeutung jener Länder weniger klar erkannt. Erst nach der Errichtung eines kommunistischen Regimes auf Kuba und nach der Kuba-Krise im Jahre 1962 wurde der deutschen und der europäischen Öffentlichkeit bewußt, daß in der westlichen Hemisphäre eine Bedrohung des Kräftegleichgewichts eingetreten war, und man erkannte die Notwendigkeit, die lateinamerikanischen Länder mehr als bisher in die Gemeinschaft der freien Völker einzubeziehen." Vgl. Referat I B 2, Bd. 512.

4 Staatssekretär Carstens besuchte vom 28. Juni bis 17. Juli 1966 Bolivien, Argentinien und Brasilien. Vgl. dazu AAPD 1966, II, Dok. 221.

Staatssekretär Lahr besuchte vom 29. Juli bis 9. August 1966 Chile und Kolumbien. Vgl. dazu AAPD 1966, II, Dok. 246. 
Herr Böker verwies dann auf die im Mai 1963 von der damaligen lateinamerikanischen Botschafterkonferenz beschlossenen „Thesen von Cuernavaca“, in denen vor allem eine Intensivierung des politischen Gedankenaustausches gefordert worden sei. ${ }^{5}$ Dies Ziel müsse deutscherseits trotz einer oft feststellbaren gewissen Apathie auf der Gegenseite beharrlich weiter verfolgt werden.

Herr Meyer-Lohse erläuterte hierauf die in Abschnitt A II der Aufzeichnung enthaltenen Einzelvorschläge wie folgt:

1) Für 1968 sei der Staatsbesuch des Präsidenten von Kolumbien Dr. Lleras Restrepo für die Zeit vom 13.-18. Mai fest vereinbart. ${ }^{6}$

Staatssekretär Lahr wies auf die Wichtigkeit hin, Herrn Bundesminister Schiller an den Gesprächen zu beteiligen.

Herr Noebel betonte, zur Erzielung der notwendigen Öffentlichkeitswirkung müsse das BPA intensiv eingeschaltet werden.

Herr Meyer-Lohse fuhr fort: Für 1969 sei daran gedacht, den Präsidenten von Uruguay $^{7}$ zu einem Staatsbesuch einzuladen. Weiterhin bestünde noch eine "standing invitation" für den Präsidenten von Venezuela ${ }^{8}$. Es sei jedoch fraglich, ob ein Besuch wegen der Neuwahl des Präsidenten in diesem Jahr schon 1969 zustande kommen könne.

An Staatsbesuche des Herrn Bundespräsidenten in Lateinamerika sei bis zu dessen Neuwahl 1969 nicht gedacht. Für 1970 könnte eine Reise nach Uruguay, Kolumbien und eventuell Venezuela ins Auge gefaßt werden.

2) Der Herr Bundeskanzler habe die Absicht geäußert, Lateinamerika zu besuchen. Staatssekretär Duckwitz bemerkte hierzu, 1968 sei eine solche Reise nicht mehr möglich.

3) Hinsichtlich der vorgesehenen Reisen des Herrn Bundesministers und der Herren Staatssekretäre in Verbindung mit der für die Zeit vom 14.-18. Oktober in Lima geplanten Botschafterkonferenz ${ }^{9}$ (Ziff. 3, 5 und 7 der Aufzeich-

5 Zur Botschafterkonferenz vom 26. bis 31 . Mai 1963 vgl. die Aufzeichnung des Referats I B 2 vom 5. Juni 1963; VS-Bd. 391 (Büro Staatssekretär); B 150, Aktenkopien 1963. Vgl. dazu auch AAPD 1963, II, Dok. 195.

In den 16 ,Thesen einer deutschen Lateinamerikapolitik“ vom 5 . Juni 1963 wurde u. a. ausgefürt: „6) Wir müssen bemüht sein, das politische Gespräch mit den lateinamerikanischen Ländern zu intensivieren und zu vertiefen, um den Lateinamerikanern unsere Anteilnahme an ihren Problemen und Nöten zu beweisen, um ihr Interesse an europäischen Problemen zu wecken und um ihnen das Gefühl der Schicksalverbundenheit mit uns und der gemeinsamen weltpolitischen Verantwortung zu geben. In diesem Rahmen können wir ihnen auch am besten unsere besonderen deutschen Anliegen (Wiedervereinigung Berlin, Ausschaltung der SBZ) näherbringen. 7) Für das Bestreben vieler lateinamerikanischer Regierungen und Parteien, eine ,unabhängige' Außenpolitik zu betreiben, sollten wir Verständnis zeigen. Der Tendenz, Lateinamerika in den afro-asiatischen Block hineinzuziehen, müssen wir jedoch entgegenarbeiten und demgegenüber das Bewußtsein des gemeinsamen europäischen Erbes wachhalten." Vgl. VS-Bd. 2535 (I B 2); B 150, Aktenkopien 1963 .

6 Der Besuch des kolumbianischen Präsidenten wurde ohne neue Terminvereinbarung verschoben. Vgl, dazu die Aufzeichnung des Vortragenden Legationsrats I. Klasse Meyer-Lohse vom 19. März 1968; Ministerbüro, Bd. 365.

7 Jorge Pacheco Areco.

8 Raul Leoni.

9 Bundesminister Brandt besuchte vom 17. bis 27. Oktober 1968 Chile, Argentinien, Uruguay und Brasilien. Staatssekretär Lahr hielt sich vom 30. September bis 14. Oktober in Guatemala, El Salvador, Honduras, Nicaragua, Costa Rica und Panama auf. Staatssekretär Duckwitz besuchte vom 23. November bis 10. Dezember 1968 Mexiko, Venezuela, Kolumbien, Peru, Paraguay und Brasilien. 
nung) erläuterte Herr Meyer-Lohse die als Anlage $2^{10}$ beigefügte vorläufige Reiseplanung, die zustimmend aufgenommen wurde.

Da StS Lahr vor, StS Duckwitz nach der Botschafterkonferenz zu reisen beabsichtige, werde eine Umstellung der bisher üblichen Themenfolge der Konferenz notwendig sein, indem die wirtschaftlichen und kulturellen Fragen zuerst, die der Politik und Verwaltung am Ende behandelt würden.

4) Folgende andere Kabinettsmitglieder hätten die Absicht zu Lateinamerikabesuchen im Jahre 1968 geäußert: Bundesminister Wischnewski für Argentinien, Brasilien und Chile; Bundesminister Stoltenberg möglicherweise nach Argentinien $^{11}$ (zur Unterzeichnung eines Abkommens über wissenschaftlichtechnische Zusammenarbeit); Bundesminister Leber möglicherweise Bolivien (etwaiger Lufthansa Eröffnungsflug); ob Bundesminister Lücke möglicherweise nach Mexiko zur Eröffnung der Olympiade ${ }^{12}$ zu reisen wünsche, sei noch ungeklärt. Eine Koordination aller Reisen sei erforderlich und werde in die Wege geleitet.

5) Konsultationen mit Brasilien und eventuell Mexiko (Ziff. 8 der Aufzeichnung) sollten in lockerer Folge ohne Institutionalisierung durchgeführt werden. Als nächste Gelegenheit böten sich hierfür die vorgesehenen Besuche der Außenminister von Mexiko ${ }^{13}$ im Juni und Brasilien ${ }^{14}$ im Mai an.

6) Die Reise einer Delegation des Deutschen Bundestages nach Lateinamerika im Jahre 1966 habe sich sehr bewährt. ${ }^{15} \mathrm{Da} 1967$ keine vergleichbare Delegation reisen konnte, sei für 1968 die Entsendung von zwei Delegationen vorgeschlagen worden. Leider habe der Deutsche Bundestag bisher noch nicht hierauf reagiert. Herr Meyer-Lohse bat Herrn Ritzel (L 1), sich beim Deutschen Bundestag für eine baldige positive Entscheidung einzusetzen.

7) Auch die Reisen lateinamerikanischer Parlamentarier nach Deutschland hätten durchweg ein gutes Echo gehabt. 1967 seien 73 in Deutschland zu Gast gewesen, 1968 leider erst 7. Der Anteil von Parlamentariern an den Informationsreisen auf Besucherquote sollte nach Möglichkeit angehoben werden.

Herr Böker bemerkte hierzu, diese Parlamentarier-Einladungen seien besonders wichtig, sie müßten allerdings seitens des Deutschen Bundestages gut behandelt werden, was in der Vergangenheit nicht immer der Fall gewesen sei.

10 Dem Vorgang beigefügt. Für die undatierte Aufzeichnung „Vorläufige Planung. Lateinamerikareise des Herrn Bundesministers und der Herren Staatssekretäre“ vgl. Referat I B 2, Bd. 582.

11 Bundesminister Stoltenberg besuchte vom 23. März bis 5. April 1969 Peru, Brasilien und Argentinien.

12 Die XIX. Olympischen Sommerspiele wurden am 12. Oktober 1968 eröffnet.

13 Antonio Carrillo Flores.

14 Der brasilianische Außenminister de Magalhaes Pinto besuchte vom 9. bis 13. Juni 1969 die Bundesrepublik.

15 Vom 29. Mai bis 18. Juni 1966 besuchte eine Gruppe von vier Mitgliedern des Bundestages Chile, Peru, Panama, Costa Rica und Venezuela. Über den Besuch in Chile berichtete Botschafter von Nostitz-Drzewiecki, Santiago de Chile: „Chile [war] erste Station und Schwerpunkt einer Informationsreise der vier Bundestagsabgeordneten Klee (CDU), Lenz (CDU), Hellige (FDP) und Matthöfer (SPD) nach Süd- und Mittelamerika. Der Aufenthalt vom 29. Mai bis 5. Juni 1966 gab durch seine Fülle von Kontakten reichlich Gelegenheit, ,Experiment Frei“ kennenzulernen. Höhepunkt der Tage in Santiago war eine dreiviertelstündige Audienz bei Staatspräsident Frei [...]. Die Abgeordneten haben durch ihr Auftreten zur Festigung der deutsch-chilenischen Beziehungen wesentlichen Beitrag geleistet." Vgl. den Schriftbericht vom 7. Juni 1966; Referat I B 2, Bd. 442. 
Herr Borchardt wies darauf hin, daß der Anteil der Parlamentarier an den Quotenreisen für Lateinamerika stärker sei als für jeden anderen Kontinent.

8) Das in Ziff. 12 der Aufzeichnung vorgeschlagene Frühstück des Herrn Bundesministers für die Gruppe der lateinamerikanischen Botschafter sei als Beweis des deutschen Kontaktwillens besonders wichtig.

Graf Welczeck teilte hierzu mit, der Herr Bundesminister habe zugestimmt, ein solches Frühstück zu geben, „wenn ein besonderer Anlaß vorläge“.

StS Duckwitz und StS Lahr erklärten übereinstimmend, dieses Frühstück solle kurz vor der Botschafterkonferenz im Oktober gegeben werden.

9) Abschließend ging Herr Meyer-Lohse noch auf einige Probleme ein, die über den rein politischen Rahmen herausragen, und zwar:

a) Die Sorge der lateinamerikanischen Länder vor der Einfuhrpolitik der EWG und ihre daherrührende verstärkte Hinwendung zum Osthandel;

b) das sehr starke Engagement der lateinamerikanischen Länder für die Entwicklungsländer auf der UNCTAD in New Delhi ${ }^{16}$;

c) die besondere Wichtigkeit der Bildungshilfe im Hinblick auf die kommunistischen Bemühungen um die lateinamerikanischen Universitäten;

d) die Problematik der oft den Rahmen der gesellschaftspolitischen Bildungsarbeit sprengenden Tätigkeit der politischen Stiftungen, und

e) die Notwendigkeit, unsere Ein-Mann-Botschaften in Mittelamerika mit einem zweiten Herrn des höheren Dienstes zu versehen.

$\mathrm{Zu}$ diesem letzten Punkt kam es zu einer kurzen Debatte, als deren Ergebnis übereinstimmend festgestellt wurde, daß eine Schließung schon vorhandener Botschaften politisch nicht möglich sei und daß im Rahmen der haushaltsmäßigen Möglichkeiten die Ein-Mann-Botschaften eine zweite Stelle des höheren Dienstes erhalten sollten.

Herr Harkort referierte zusammenfassend über die wirtschaftspolitischen Beziehungen zu Lateinamerika (Abschn. B der Aufzeichnung). Er gab folgende Bewertungen:

1) Der Handel funktioniere einigermaßen befriedigend bis auf das Problem der Einfuhrbeschränkungen der EWG.

2) Die deutschen Privatinvestitionen in Lateinamerika hätten $44 \%$ der gesamten deutschen Überseeinvestitionen erreicht, dies sei kein schlechtes Ergebnis.

3) Der Anteil Lateinamerikas an der deutschen Kapitalhilfe betrage bisher $7,7 \%$; er solle in diesem Jahr auf $15 \%$ gesteigert werden.

16 Die Zweite Konferenz für Handel und Entwicklung der Vereinten Nationen (UNCTAD) fand vom 1. Februar bis 29. März 1968 statt. Sie sprach u.a. die Empfehlung zur Leistung von Entwicklungshilfe in Höhe von $1 \%$ des Bruttosozialproduktes der wirtschaftlich fortgeschrittenen Staaten aus. Ferner wurde eine Resolution zur Einsetzung eines Ausschusses über die Einführung eines allgemeinen nichtdiskriminierenden Zollpräferenzsystems verabschiedet. Zum Ergebnis der Konferenz stellte das Bundesministerium für Wirtschaft fest, „daß diese Entschließungen nicht mit rechtlicher Verbindlichkeit für die Mitglieder der Welthandelskonferenz ausgestattet sind. Es handelt sich vielmehr um Empfehlungen, deren Gewicht im Politischen liegt." Die Ergebnisse seien daher von den meisten Entwicklungsländern ,als spärlich und enttäuschend bezeichnet worden. Die Konferenz hat indessen gezeigt, daß der anfangs einheitlich erscheinende Block der Entwicklungsländer in Wirklichkeit, entsprechend dem wirtschaftlichen und sozialen Niveaugefälle unter diesen Ländern, sehr verschiedenartige Interessen in sich vereint.“ Vgl. die Anlage zum Vermerk des Referats III A I vom 14. August 1968, Referat I B 1, Bd. 441. 
4) Bei der Technischen Hilfe betrage der Anteil Lateinamerikas bereits jetzt $16,3 \%$. Hier seien besonders gute Ergebnisse erzielt worden.

Insgesamt sei keine sensationelle Änderung zu erwarten. Die schon bisher betriebene „Politik der kleinen Schritte“, um möglichst viel für Lateinamerika herauszuholen, solle fortgesetzt werden. Das Klima hierfür sei im ganzen gut.

Auf die von Herrn Meyer-Lohse aufgeworfenen handelspolitischen Probleme (vgl. oben a) und b)) eingehend, erklärte Herr Harkort weiter: Im Rahmen der EWG sei es besonders wichtig, das Bananen-Protokoll ${ }^{17}$ gegen den Widerstand Frankreichs und der assoziierten francophonen afrikanischen Länder zu erhalten, das Deutschland die unbeschränkte Einfuhr lateinamerikanischer Bananen ermögliche. Die Aussichten der lateinamerikanischen Fleischexporteure seien dagegen schlecht, da hier nicht nur sämtliche EWG-Partner, sondern auch das BML sich einer Liberalisierung widersetze. Die Präferenzen für die assoziierten afrikanischen Länder, die den besonderen Unwillen der Lateinamerikaner erregten, seien seinerzeit gegen deutschen Widerstand durchgesetzt worden. Man müsse den Versuch eines allmählichen Abbaus machen. Auf die Frage von StS Duckwitz, ob für die lateinamerikanischen Länder eine Assoziierung in Frage komme, entgegnete Herr Harkort, daß dies nicht praktikabel sei. Auf die UNCTAD eingehend bemerkte Herr Harkort, daß die Brasilianer zwar verbal sehr stark aufträten, dies aber praktisch wahrscheinlich nicht viel bedeute. Von den durch die OECD vorgeschlagenen Universalpräferenzen würden die höher entwickelten lateinamerikanischen Länder wahrscheinlich mehr profitieren als irgend jemand sonst. In bezug auf die von lateinamerikanischer Seite wiederholt geforderten weltweiten Rohstoffabkommen wies Herr Harkort darauf hin, daß das internationale Kaffee-Abkommen ${ }^{18}$ bereits bestehe und ein internationales Kakao-Abkommen möglicherweise noch 1968 abgeschlossen werden könne. Er wiederholte abschließend, daß insgesamt keine Sensationen zu erwarten seien, aber gute Möglichkeiten einer positiven Weiterentwicklung bestünden.

StS Duckwitz schloß wegen der fortgeschrittenen Zeit die Sitzung. Die noch ausstehenden Fragen der Öffentlichkeitsarbeit und Kulturpolitik sollen auf einer möglichst bald anzuberaumenden weiteren Sitzung behandelt werden. ${ }^{19}$

Referat I B 2, Bd. 582

17 Für den Wortlaut des „Protokolls über das Zollkontingent für die Einfuhr von Bananen“ vom 25. März 1957 vgl. BundesgesetzblatT 1957, Teil II, S. 1008-1010.

18 Für den Wortlaut des Internationalen Kaffee-Abkommens vom 28. September 1962 vgl. UNTS, Bd. 469, S. 169-245.

19 Am 12. März 1968 fand im Auswärtigen Amt eine zweite Hausbesprechung zur Lateinamerikapolitik statt. Ministerialdirektor Werz wies , in einem allgemeinen Uberblick auf die große Aufnahmebereitschaft der Lateinamerikaner für die abendländisch-europäische Kultur hin. Die deutsche Kultur stehe seit Humboldt in hohem Ansehen. Man baue daher auf einem breiten Fundament an Prestige auf. Die regionalen Schwerpunkte der deutschen Kulturarbeit lägen in Argentinien, Brasilien, Chile und Mexiko“. Er führte weiter aus: „Ein großes Reservoir für die deutsche Kulturarbeit bilden die Deutschstämmigen in Lateinamerika. Nach jahrelanger Zurückhaltung kann heute festgestellt werden, daß diese Gruppen politisch in den südamerikanischen Ländern voll integriert sind, und daß die Gastländer selbst den deutschstämmigen Gruppen vorurteilsfrei gegenüberstehen." Vgl. Referat I B 2, Bd. 582. 
86

\section{Botschafter Grewe, Brüssel (NATO), an das Auswärtige Amt}

\author{
Z B 6-1-11471/68 geheim \\ Fernschreiben Nr. 378
}

\author{
Aufgabe: 5. März 1968, $19.30 \mathrm{Uhr}^{1}$ \\ Ankunft: 5. März 1968, 21.30 Uhr
}

Auf DE Nr. 427 vom 29.2. (Plurex) II A 7-83²

Betr.: Deutschland-Kontrolle als Bündniszweck

1) Die Vertretung begrüßt die Erklärung von Generalsekretär Brosio in Washington, daß man auf seiten der Verbündeten aufhören solle, die NATO als Instrument zur Kontrolle Deutschlands zu bezeichnen (vgl. Ziff. des Bezugsberichts). Hinweise dieser Art scheinen um so angebrachter, als in letzter Zeit wiederholt Äußerungen der von Brosio kritisierten Art festgestellt werden konnten.

Als Beispiel führe ich an:

a) den Artikel Sulzbergers in der "New York Herald Tribune“ vom 24.1.68: „... NATO in reality is an alliance against Russia, the greatest potential enemy, and also against West Germany, the most powerful European member...";

b) die Erklärung des niederländischen Ministerpräsidenten de Jong in einer Fernsehsendung anläßlich der Bekanntgabe einer Meinungsumfrage über die Einstellung der niederländischen Öffentlichkeit zur NATO (12.2.68): Ein Austritt der Niederlande aus dem Bündnis werde zur Desintegration in Europa

1 Hat Staatssekretär Duckwitz vorgelegen.

Hat Legationsrat Gehl am 11. März 1968 vorgelegen, der handschriftlich vermerkte: „H[err]n D II (Ref[erat] II A 7) unter Hinweis auf die Anregung des H[err]n StS“.

Hat Ministerialdirektor Ruete am 17. März 1968 vorgelegen, der für Referat II A 7 handschriftlich vermerkte: „Bitte für Rede Min[ister] notieren.“

Vgl. Anm. 9.

2 Mit Drahtbericht Nr. 427 berichtete Gesandter von Lilienfeld, Washington, über den Besuch des NATO-Generalsekretärs in Washington: „Brosio habe sich sehr für die deutschen Belange eingesetzt und die entscheidende Bedeutung der Bundesrepublik für das Bündnis betont. Angesichts der naturgemäß langsamen Fortschritte in der deutschen Ostpolitik und dem sowjetischen Verhalten in der Nichtverbreitungsfrage halte er es für unbedingt notwendig, daß keinerlei Zweifel der Unterstützung der Bundesregierung durch die NATO-Partner aufkommen könne. Auch habe er sich dafür ausgesprochen, daß man westlicherseits aufhören sollte, die NATO auch als ein Instrument zur Kontrolle Deutschlands zu rechtfertigen. Schließlich habe er um Verständnis für die deutsche Reaktion auf die sowjetischen Bemühungen, die Nichtverbreitungsfrage gegen die Bundesregierung auszuspielen, geworben und gefordert, daß diesen durch eine stärkere Betonung des weltweiten Charakters des Abkommens entgegengewirkt werde." Der Drahtbericht wurde mit Drahterlaß Nr. 900 am 1. März 1968 an die Ständige Vertretung bei der NATO in Brüssel übermittelt. Vgl. VS-Bd. 1659 (II A 7); B 150, Aktenkopien 1968.

3 In dem Artikel „A New Look at NATO“ wurde u. a. ausgeführt: „Politically, the implications are more complicated. NATO in reality is an alliance against Russia, the greatest potential enemy, and also against West Germany, the most powerful European member. This is an inherent paradox and weakness. It will be underscored in the inescapable crisis that must eventually be caused by shrinkage of U.S. contributions. The relative power of Germany within the alliance must increase as the American presence diminishes. Neither France, which has a small nuclear force but only two divisions half-heartedly assigned to NATO, nor Britain, can offset Bonn's 12 divisions. Thus the German role and inevitably the German voice inside NATO are bound to rise and this will excite Soviet suspicions because, of all the allies, Moscow suspects Germany most. ${ }^{\text {V Vgl. NEW YORK }}$ HERALD TRIBUNE, NR. 26447 vom 24. Januar 1968, S. 4. 
führen mit der Folge, daß ein wiederbewaffnetes Deutschland Ost und West dann vor zahllose neue Probleme stellen werde ...4 in einer atomwaffenfreien Zone, die nach den Vorstellungen Rapackis mit der allmählichen Abschaffung der NATO und des Warschau-Paktes einhergehen sollte, bliebe Deutschland wiederum sich selbst überlassen mit der möglichen Folge eines Wiedererwachens des deutschen Nationalismus (vgl. DB Nr. 88 der Botschaft Den Haag vom 13.2 .68$)^{5}$;

c) die genannte Meinungsumfrage, die u. a. dem Zweck diente, die NATO in der niederländischen Öfentlichkeit attraktiver zu machen, z. B. mit der SuggestivFrage: „Is it owing to NATO that Western Germany has no nuclear power?“;

d) die von der niederländischen Zeitung „Frouw“ hierzu veröffentlichte Glosse, nach der „das Bündnis Europa vor der Wiederauferstehung deutscher Militärmacht und nicht vor Zugriff sowjetischer Expansion schützen soll“ (FS Nr. 97 vom 16.2.68 aus Den Haag) ${ }^{6}$;

e) den in der „Times“ am 6.2.68 veröffentlichten Leserbrief des Oberkommandierenden der Britischen Rheinarmee, General Sir John Hackett, der u. a. feststellte, es sei Aufgabe, den legitimen Verteidigungsbedürfnissen der Bundesrepublik in einem Verteidigungssystem nachzukommen, „das nicht von den Deutschen dominiert wird. "7

Diese Äußerungen finden ihre Ergänzung in Mitteilungen hoher britischer Angehöriger des NATO-Generalsekretariats, daß britische Labour-Politiker, die sich bisher für einen britischen Truppenabzug aus dem Bundesgebiet einsetzen, unter dem Eindruck einer angeblichen Stärkung des Rechtsradikalismus in Deutschland bereit seien, ihren Standpunkt zu überprüfen.

f) die Erklärung des Vorstandes des British Atlantic Committee, das die Ausführungen von Sir John Hackett unterstützt und dabei als eines der drei wichtigen Ziele der Allianz bezeichnet: „die potentielle Macht der Bundesrepublik unter Kontrolle zu halten."

2) Ich möchte die politische Bedeutung dieser Äußerungen, die im übrigen von unterschiedlicher Qualität sind, in keiner Weise überbewerten. Gleichwohl sollten sie m. E. nach fast 14 Jahren deutscher NATO-Mitgliedschaft nicht einfach hingenommen werden. Auch wenn es schwerfallen dürfte, solche Stimmen

4 Auslassung in der Vorlage.

5 Botschafter Knoke, Den Haag, berichtete weiter: „Die Sendung wurde mit der Bekanntgabe eines Umfrageergebnisses abgeschlossen, demzufolge 85 Prozent der Befragten die weitere Mitgliedschaft der Niederlande in der NATO befürworteten. In diesem Ergebnis dürfte sich auch die aus de Jongs Ausführungen deutlich werdende Auffassung widerspiegeln, daß die NATO in den Niederlanden nicht nur als Bollwerk gegen mögliche kommunistische Aggressionen, sondern mindestens ebenso sehr als Sicherung gegen eine Renationalisierung Deutschlands angesehen wird." Vgl. Referat II A 7, Bd. 1179.

6 Für den Drahtbericht des Botschafters Knoke, Den Haag, vgl. Referat II A 7, Bd. 1179.

7 In dem Leserbrief „Defining the True Purpose of NATO: What should be understood“ wurde u.a. ausgeführt: „What, for our part, have we to do, we in the West? We must do two things. The first is to maintain in being and suitably located a force sufficient in size, capability and readiness to make sure that the Soviet force, even though superior in strength to our own, would be unable to guide events in the sole interest of the U.S.S.R. The second is to ensure that the legitimate defensive requirements of the Federal Republic of Germany are met in a military system which the Germans do not themselves dominate. This last provision is of very high importance and is widely recognized to be so by moderate opinion in the Federal Republic of Germany."Vgl. THE TIMES, Nr. 57168 vom 6. Februar 1968, S. 9. 
zum Schweigen zu bringen, sollte Tendenzen dieser Art doch entgegengewirkt werden. Ich denke insbesondere auch daran, daß z. B die niederländischen ÄuBerungen im Zusammenhang mit den an sich begrüßenswerten Bemühungen erfolgten, der niederländischen Öffentlichkeit ein Verbleiben in der NATO nach 1969 wünschenswert erscheinen zu lassen. Die Urheber solcher Äußerungen nehmen offenbar in Kauf oder sind sich dessen nicht bewußt, daß sie damit u.U. bestimmten Kritikern der NATO in der Bundesrepublik Deutschland Ansatzpunkte liefern, um eine Überprüfung unseres Verhältnisses zur NATO zu fördern.

Wir sollten m.E. nicht scheuen, in dieser Frage eine besondere Empfindlichkeit zur Schau zu tragen. ${ }^{8}$ Zum mindesten könnten wir erreichen, daß solche Äußerungen nicht in offiziellen Erklärungen und Dokumenten auftauchen.

3) Ich darf anregen, dem Problem dort Aufmerksamkeit zu schenken und es gegenüber den in Frage kommenden ausländischen Regierungskreisen ggf. deutlich auszusprechen. ${ }^{9}$ Ich selbst behalte mir vor, bei passender Gelegenheit eine entsprechende Warnung anklingen zu lassen, z. B. wenn hier - etwa im Zuge der Diskussion der „Follow-up-measures“ der Harmel-Studie - Tendenzen oder Äußerungen einzelner Mitgliedregierungen bekannt werden, die den Fortbestand der NATO mit Argumenten der oben genannten Art zu rechtfertigen suchen.

[gez.] Grewe

VS-Bd. 1659 (II A 7)

8 Am 12. März 1968 nahm Botschafter Knoke, Den Haag, dazu Stellung: „Zu der Anregung unserer NATO-Vertretung in Brüssel möchte ich aus hiesiger Sicht bemerken, daß wir keine besondere Empfindlichkeit zur Schau tragen sollten. Wir sollten vielmehr andere unauffällig dafür gewinnen, daß sie - wie Generalsekretär Brosio es anerkennenswerterweise schon getan hat - uns in Schutz nehmen. Jede nach außen zur Schau getragene Empfindlichkeit würde $z$. B. für die Niederländer nur ein Beweis sein, daß sie mit ihrem Mißtrauen recht hätten." Vgl. den Drahtbericht $\mathrm{Nr}$. 152; VS-Bd. 2711 (I A 3); B 150, Aktenkopien 1968.

9 Ministerialdirigent Sahm teilte der Ständigen Vertretung bei der NATO in Brüssel am 18. März 1968 mit: „Es ist vorgeschlagen worden, daß der Herr Bundesminister bei der nächsten NATOMinisterkonferenz in Reykjavik eine Bemerkung zu diesem Thema in seine Rede einfließen laßß." Vgl. den Drahterlaß Nr. 191; VS-Bd. 1659 (II A 7); B 150, Aktenkopien 1968. 


\section{Aufzeichnung des Staatssekretärs Duckwitz}

\section{St.S. 479/68 VS-vertraulich}

6. März 1968

Bei meinen kürzlichen Gesprächen in Washington ${ }^{1}$ ist von meinen amerikanischen Gesprächspartnern die Frage der Anerkennung der Oder-Neiße-Grenze mehrfach erwähnt worden. Es ging deutlich aus diesen Äußerungen hervor, daß man eine Entschließung der Bundesregierung, diese Grenze anzuerkennen, als eine Erleichterung der gesamten außenpolitischen Lage betrachtet und als einen bedeutenden Entspannungsbeitrag der Bundesrepublik wertet.

Ich habe in dieser Frage schon seit Jahren den gleichen Standpunkt eingenommen. Die Washingtoner Gespräche veranlassen mich, meine Gedanken zu dieser Frage noch einmal kurz niederzulegen:

Der Ausgangspunkt aller Überlegungen ist die nicht gern gehörte, aber unwiderlegliche Tatsache, daß wir den letzten Krieg vom Zaun gebrochen und verloren haben. Dafür muß, wie die Geschichte lehrt, nun einmal bezahlt werden. Die Alliierten haben die Entschädigung der Polen für ihre im Osten verlorengegangenen Gebiete durch entsprechenden Gebietszuwachs im Westen anerkannt. Die endgültige Regelung dieses von allen als berechtigt anerkannten polnischen Anspruchs soll in einem Friedensvertrag mit einer gesamtdeutschen Regierung erfolgen, wobei sich jeder darüber klar ist, daß ein Friedensvertrag in übersehbarer Zeit ebenso wenig zu erreichen ist wie die Bildung einer gesamtdeutschen Regierung. Die DDR hat die Oder-Neiße-Grenze als endgültige polnische Westgrenze anerkannt. ${ }^{2}$ Wir weigern uns unter Hinweis auf einen materiell gänzlich wertlosen Vorbehalt. Wir wissen, daß wir in dieser Frage völlig allein stehen. Für die Welt, einschließlich unserer Verbündeten, ist die Oder-Neiße-Grenze die endgültige westliche Grenze Polens. Ein Friedensvertrag, hinter den wir uns verschanzen, wird nur den jetzigen Zustand bestätigen. Unser Einverständnis wird somit nicht mehr Gegenstand eines „Aushandelns“ sein können. Es wäre nur noch ein Registrierungsobjekt, über das man zur Tagesordnung übergeht.

Wir werden, wenn wir es auf einen „Friedensvertrag“ ankommen lassen, zwangsläufig unsere Zustimmung geben müssen, ohne auch nur einen ideellen Gegenwert - von dem materiellen, der spätestens noch 1958 möglich war, ganz zu schweigen - zu erzielen. Sprechen wir dagegen heute und freiwillig unsere Anerkennung dieser Tatsache gewordenen Grenze aus, so können wir bei entsprechender wohlvorbereiteter Präsentation diese unsere Anerkennung als einen für uns besonders schwerwiegenden und schmerzlichen Beitrag zur Ent-

1 Staatssekretär Duckwitz hielt sich vom 26. bis 29. Februar 1968 in den USA auf. Zu den Gesprächen mit dem Abteilungsleiter im amerikanischen Außenministerium, Leddy, am 28. Februar sowie Außenminister Rusk und Staatssekretär Eugene Rostow am 29. Februar 1968 vgl. Dok. 76, Dok. 77, und Dok. 84.

2 Die DDR erkannte im Abkommen vom 6. Juli 1950 über die Markierung der festgelegten und bestehenden polnisch-deutschen Staatsgrenze (Gürlitzer Vertrag) die Oder-Neiße-Linie als Grenze zu Polen an. Für den Wortlaut des Abkommens vgl. AUSSENPOLITIK DER DDR I, S. $342 \mathrm{f}$. 
spannung in der Welt und als Demonstration unseres immer wieder angezweifelten Willens zur friedlichen Verständigung und Entspannung herausstellen. Nur bei einer solchen freiwilligen Anerkennung können wir als einzig noch mögliches „Handelsobjekt" einen weltweiten Goodwill erzielen. Außerdem wäre dem immer wieder mit unserer ablehnenden Haltung begründeten Vorwurf des Revanchismus die Spitze genommen. Aber wir müssen selbst handeln; wir dürfen uns nicht zu dieser Handlung zwingen lassen. Sie würde sonst wertlos. Hiermit dem Herrn Minister ${ }^{3}$ vorgelegt.

Duckwitz

VS-Bd. 480 (Büro Staatssekretär)

88

\section{Bundesminister Brandt, z.Z. Berlin (West), an Staatssekretär Duckwitz}

Z B 6-1-11492/68 geheim

Fernschreiben Nr. 35

Citissime
Aufgabe: 6. März 1968, 14.40 Uhr

Ankunft: 6. März 1968, 15.10 Uhr

\section{Für Herrn StS Duckwitz}

An der Besprechung über Gewaltverzicht nahmen heute im Berliner Bundeshaus ${ }^{1}$ außer dem Herrn Bundeskanzler und mir teil: Bundesminister Wehner, Schröder, Heck, Abg. Stücklen, StS Carstens und Guttenberg.

Es herrschte Einigkeit, daß bald geantwortet werden soll..$^{2}$ Die zunächst strittige Frage, ob wir auch auf die zusätzlich zum Gewaltverzicht aufgeworfenen Sachfragen eingehen sollen, wurde so beantwortet:

Die sowjetische Seite hat nach unserer Meinung gefragt. Demzufolge sollten wir unseren Standpunkt darlegen. ${ }^{3}$ Bereitschaft erklären, in Verhandlungen über Gewaltverzicht unsere Auffassungen im einzelnen darzulegen. Bei den Einzelfragen sollten wir uns, wenn möglich, noch mehr als geschehen auf Regierungserklärungen beziehen.

Bundeskanzler: „Offensiv“ argumentieren im Sinne unseres Rechtsstandpunktes, unserer Glaubwürdigkeit und unseres guten Willens. An die indirekten Adressaten (Polen, ČSSR) denken und ihnen gegenüber „mit Wärme“ argumentieren.

3 Hat Bundesminister Brandt am 8. März 1968 vorgelegen, der handschriftlich vermerkte: „Bitte R[ücksprache]!“

1 Vom 4. bis 8. März 1968 fand in Berlin (West) eine Parlamentarische Arbeitswoche des Bundestages statt.

2 Zum sowjetischen Memorandum vom 29. Januar 1968 vgl. Dok. 32, besonders Anm. 9.

3 Zum Entwurf eines Aide-mémoires vom 31. Januar 1968 vgl. Dok. 39. 
Wehner: Deutlich machen, daß wir die Karlsbader Beschlüsse ${ }^{4}$ kennen. Sagen, daß wir alle umstrittenen Fragen durch Gewaltverzicht lösbar machen wollen.

Schröder und Stücklen hielten es für wünschenswert, Text eines deutschen Entwurfs für Gewaltverzichterklärung (oder dessen Skizzierung) in die Antwort aufzunehmen.

Stücklen bat zu berücksichtigen, daß über Zustimmung zum NV-Vertrag noch nichts entschieden ist.

S. 5 a: Hinweis auf mögliches regionales NV-Abkommen sollte entfallen. ${ }^{5}$

Im übrigen habe ich die Fragen beantwortet, die in der Aufzeichnung vom 4. d.M. ${ }^{6}$ gestellt wurden.

Wir sollten jetzt versuchen, die redaktionelle Überarbeitung in den nächsten Tagen vorzunehmen. ${ }^{7}$

VS-Bd. 10065 (Ministerbüro)

[gez.] Brandt

89

\section{Gespräch des Bundeskanzlers Kiesinger mit dem schweizerischen Botschafter Troendle}

Ge 28-18/68 VS-vertraulich

7. März 1968 ${ }^{1}$

Aufzeichnung über ein Gespräch, das der Herr Bundeskanzler am 7. März 1968 um 11.00 Uhr mit dem schweizerischen Botschafter Dr. Max Troendle führte.

Der Botschafter legte dem Herrn Bundeskanzler dar, daß er vom schweizerischen Bundesrat beauftragt sei, ihm die Sorgen und Ansichten der schweizerischen Regierung im Hinblick auf die Verhandlungen in Brüssel zu unterbreiten. Man habe in Bern von dem deutschen 8 Punkte-Programm vom 29. Februar $^{2}$ Kenntnis genommen, sei sehr erfreut über diesen Vorschlag und wünsche ihm gutes Gelingen. Man sei bei der Lagebeurteilung zu der Schlußfolge-

$4 \mathrm{Zu}$ den Beschlüssen der Konferenz der kommunistischen und Arbeiterparteien Europas vom 24. bis 26. April 1967 in Karlový Varý (Karlsbad) vgl. Dok. 79, Anm. 4.

5 Vgl. dazu Dok. 39, besonders Anm. 25.

6 Für die Fragen in der Aufzeichnung des Ministerialdirektors Ruete vgl. Dok. 79, besonders Anm. 19-23.

7 Nach mehreren Überarbeitungen wurde das Aide-mémoire der Bundesregierung am 9. April 1968 durch Staatssekretär Duckwitz dem sowjetischen Botschafter Zarapkin übergeben. Vgl. dazu Dok. 121.

1 Die Gesprächsaufzeichnung wurde von Ministerialdirigent Boss, Bundeskanzleramt, gefertigt.

2 Für den Wortlaut der von Bundesminister Brandt auf der EG-Ministerratstagung am 29. Februar 1968 in Brüssel formulierten acht Punkte für ein Arrangement mit den Beitrittskandidaten vgl. Dok. 74. 
rung gekommen, daß sich einige deutsche Ideen, von denen man hoffe, sie mögen die Oberhand gewinnen, durchsetzen müßten.

Bei aller Hoffnung sei man aber darüber enttäuscht, daß bei den Arrangements-Vereinbarungen den Beitrittswilligen ${ }^{3}$ Priorität eingeräumt werde. Die schweizerische Regierung habe sich vor allem von der Bundesregierung erhofft, daß sie für die Schweiz eine Bresche schlagen werde, damit sie von Anfang an an den Beratungen beteiligt werde. Die Argumente, die die Schweiz allein aufgrund der Zahlen im Wirtschaftsaustausch liefern könne, seien überzeugend. Die Schweiz rangiere unter den Kunden der Bundesrepublik noch vor England. ${ }^{4}$ Im landwirtschaftlichen Bereich sei sie der größte Abnehmer der EWG.

Nach schweizerischer Auffassung könne ein Arrangement nur auf eine Freihandelszone hinauslaufen; dann aber könne den Beitrittswilligen keine Vorzugsbehandlung eingeräumt werden. Im übrigen verweise die schweizerische Regierung auf ihr bereits seit 1961 vorliegendes Verhandlungsgesuch.

Der Herr Bundeskanzler erwiderte, die Gespräche über das Verhältnis der EWG zu den Beitrittswilligen seien an einem kritischen Punkt angelangt. Der Bundesregierung habe seit langem eine Lösung vorgeschwebt, die den handelspolitischen Graben so gut wie möglich einebnet. Man habe sich auch deshalb aktiv an der Kennedy-Runde beteiligt. Den Italienern habe man in Rom gesagt, man wolle die EWG rasch weiterentwickeln, aber dabei den Graben nicht vertiefen. ${ }^{5}$ Was Frankreich wirklich wolle, sei nicht klar. Die Bundesregierung wolle sich an den Text des deutsch-französischen Kommuniqués ${ }^{6}$ halten.

Nun höre man widersprüchliche Nachrichten aus Paris, daß das Ergebnis der deutsch-französischen Konsultationen wieder eingeschränkt werden solle. Es handele sich hierbei insbesondere um den Begriff der Freihandelszone. Er gebe $\mathrm{zu}, \mathrm{da} ß$ man deutscherseits in der Interpretation ein wenig weiter gegangen sei, als dies den Besprechungen in Paris entsprochen hätte. Da aber klar sei, da $\beta$ jedes Arrangement GATT-konform sein müsse, könne ja nur eine Freihandelszone angezielt werden.

Die Gespräche zwischen Bundesminister Brandt und Couve de Murville, die inzwischen stattgefunden hätten, seien sehr enttäuschend gewesen. ${ }^{7}$

Er, der Herr Bundeskanzler, habe General de Gaulle sehr deutlich gesagt, es sei ihm bewußt, daß wir keine Druckmittel gegen Frankreich hätten und daß wir auch keinen Druck ausüben wollten, weil ein solches Verfahren nicht zum Erfolg führen würde. Aber wir müßten trotzdem vorwärtskommen. So sei es dann zu der Vereinbarung gekommen, die ganz optimistisch interpretiert werden konnte.

3 Dänemark, Großbritannien, Irland und Norwegen.

4 Im Jahr 1967 exportierte die Bundesrepublik Waren im Wert von 5042 Mio. DM in die Schweiz. Die Ausfuhren nach Großbritannien erreichten ein Volumen von 3472 Mio. DM. Vgl. STATISTISCHES JAHRBUCH 1968, S. 295.

5 Vgl. dazu die deutsch-italienischen Regierungsgespräche am 1./2. Februar 1968 in Rom; Dok. 40.

6 Für den Wortlaut der deutsch-französischen Erklärung vom 16. Februar 1968 vgl. Dok. 62, Anm. 17.

7 Anläßlich der EG-Ministerratstagung am 29. Februar 1968 in Brüssel war ein gemeinsames Frühstück des Bundesministers Brandt mit dem französischen Außenminister vereinbart. Vgl. dazu Dok. 59, besonders Anm. 6. 
Die Schweiz sei nun zu Recht unzufrieden, daß Verhandlungen nur mit den Beitrittskandidaten vorgesehen sind, doch wolle man zunächst einmal sehen, was sich dabei entwickle.

Er wolle den schweizerischen Wunsch auch dem Außenminister übermitteln. Er könne ohne weiteres sagen, daß die Einschränkung in dem deutschen 8 PunktePlan nicht in dem Sinne gemeint gewesen sei, daß die Schweiz und andere ausgeschlossen sein sollten. Man habe in Paris nicht dezidiert gesagt, daß die Erklärung nur für die vier Beitrittswilligen gelte.

Er könne die Berechtigung der Schweizer Argumente in keiner Weise leugnen. Es sei aber, das wollte er dem Schweizer Botschafter noch einmal versichern, nicht die Absicht der deutschen Politik, das Arrangement auf die Dauer auf vier Länder zu beschränken. Wichtig sei es, dafür zu sorgen, daß nun die Dinge nicht versanden würden. Es handele sich eben um den Gegensatz zwischen zwei grundverschiedenen europäischen Konzeptionen, von denen die eine wirtschaftlich und die andere hochpolitisch sei.

Frankreich wünsche die deutsche Zusammenarbeit und müsse sie auch wollen. Dabei könne es noch sehr viel Schwierigkeiten geben, die auch, wie er de Gaulle gesagt habe, in der Macht der öffentlichen Meinung in Deutschland lägen. Bismarck habe davon gesprochen, daß die Politik die Kunst des Möglichen sei. Ihm scheine es eher angebracht zu sagen, daß Politik die Kunst sei, das, was man als notwendig erkannt habe, möglich zu machen.

Der Herr Bundeskanzler und der schweizerische Botschafter kamen sodann auf den erfreulichen Stand der Integration zwischen Deutschland und der Schweiz im südbadischen Raum und auf die Wünschbarkeit einer engeren Verbindung der europäischen Länder zu sprechen, vor allen Dingen auch im Hinblick auf unvorhergesehene Entwicklungen in der Weltpolitik.

Das Gespräch schloß mit der Zusage des Herrn Bundeskanzlers, den Botschafter ständig auch über das Bundeskanzleramt über die Entwicklung der Gespräche in Brüssel auf dem laufenden zu halten.

Auf Presseanfragen sollte lediglich gesagt werden, daß der schweizerische Botschafter beim Bundeskanzler gewesen sei und ihm die Auffassung der schweizerischen Regierung zu den gegenwärtigen Verhandlungen in Brüssel vorgetragen habe.

Der schweizerische Botschafter überreichte das anliegende Papier. ${ }^{8}$

Bundeskanzleramt, AZ: 21-30 100 (56), Bd. 27

8 Dem Vorgang beigefügt. Im schweizerischen Aide-mémoire vom 7. März 1968 wurde u.a. ausgeführt: „Das schweizerische Verhandlungsgesuch vom 15. Dezember 1961 werde aber bewußt pendent gehalten, weil das damals umschriebene Ziel, nämlich ,eine Regelung zu finden, die es der Schweiz ermögliche, am weiteren Ausbau eines integrierten europäischen Marktes mitzuwirken, unter Beibehaltung der ständigen Neutralität' seine Gültigkeit nicht verloren habe." Die Schweiz sei der „weitaus wichtigste Abnehmer landwirtschaftlicher Erzeugnisse der EWG“, der „12\% der EWG-Agrarausfuhren aufnimmt und der EWG im Jahre 1967 die Erzielung des bisher höchsten Außenhandelsüberschusses gegenüber der Schweiz, nämlich 5038 Millionen Franken, ermöglicht hat. Die Schweizerische Regierung gibt der bestimmtesten Erwartung Ausdruck, daß angesichts der Eindeutigkeit der von ihr bisher eingenommenen Haltung ihre Mitwirkung bei der Behandlung der nunmehr in Diskussion stehenden Pläne gleichzeitig mit den vier Beitrittsanwärtern in Aussicht genommen wird und daß sich auch die Bundesregierung hierfür einsetzt." Vgl. Bundeskanzleramt, AZ: 21-30 100 (56), Bd. 27; B 150, Aktenkopien 1968. 


\section{Gespräch des Bundeskanzlers Kiesinger mit dem französischen Botschafter François Seydoux}

\section{Ge 28-15/68 geheim}

8. März $1968^{1}$

Vermerk über den Besuch von Herrn Botschafter Seydoux beim Herrn Bundeskanzler und Herrn Staatssekretär am 8. März 1968.

Seydoux: Couve de Murville sei wegen des deutschen Papieres ${ }^{2}$ wütend, traurig und besorgt gewesen. Er habe es als ungenießbar (imbuvable) bezeichnet. Es sei ein Cocktail verschiedener Vorschläge, von denen ein großer Teil in Paris gar nicht besprochen worden sei (Konjunktur-, Währungspolitik, EURATOM, belgische Denkschrift ${ }^{3}$, technologische Konferenz usw.). ${ }^{4}$

Staatssekretär Carstens schlug ein Treffen von BM Brandt und Couve vor der Sitzung am 9. März $z^{5}$ vor, um über das Papier zu sprechen und zu vereinbaren, wie sie in der anschließenden Sitzung prozedieren wollen; dabei sei anzustreben, in den Punkten Fortschritte zu erzielen, über die sich Deutsche und Franzosen einig waren; die anderen Punkte könnten dann generell zur Diskussion gestellt werden.

Nachdem Seydoux seine Ausführungen vor dem Herrn Bundeskanzler wiederholt hatte, besprach der Herr Bundeskanzler einige Punkte des deutschen Pa-

1 Durchdruck.

Die Gesprächsaufzeichnung wurde von Ministerialdirektor Osterheld, Bundeskanzleramt, gefertigt.

2 Am 5. März 1968 übermittelte die Bundesregierung der französischen Regierung Vorschläge für eine „handelspolitische und technologische Zusammenarbeit zwischen den Mitgliedstaaten der Europäischen Gemeinschaften und anderen europäischen Staaten“, wobei das handelspolitische Arrangement insgesamt acht Punkte umfaßte: „Dieser Vorschlag verfolgt mehrere Ziele: In erster Linie das oben angeführte Ziel, den späteren Beitritt der beitrittswilligen Länder im Interesse aller zu erleichtern. Zum anderen soll es einen Beitrag der Gemeinschaft zu dem von Großbritannien in Angriff genommenen Werk der Konsolidierung seiner Wirtschafts- und Währungslage darstellen, indem es die Basis des britischen Außenhandels zu erweitern hilft; darüber hinaus wird es diesen Konsolidierungsprozeß unterstützen, indem es ihn in die Perspektive des von allen gewünschten Beitritts Großbritanniens zur Gemeinschaft stellt. “ In der Frage der technologischen Zusammenarbeit halte die Bundesregierung am Beschluß der EG-Ministerratstagung vom 31. Oktober 1967 fest: „Die deutsche Regierung hält diesen Beschluß nach wie vor für richtig und meint, $\mathrm{da}$ seine Durchführung fortgesetzt werden sollte, zumal bereits einige Arbeitsergebnisse erzielt worden sind und diese in eben die Richtung weisen, auf die es im vorliegenden Zusammenhang ankommt: Möglichkeiten verstärkter Zusammenarbeit mit Großbritannien und den anderen Beitrittskandidaten zu finden. “ Die Vorschläge wurden am 9. März 1968 dem EG-Ministerrat unterbreitet. Vgl. EUROPA-ARCHIV 1968, D 141-144.

3 Zum belgischen Memorandum vom 29. Februar 1968 vgl. Dok. 74, Anm. 7.

4 Bereits am 7. März 1968 erklärte der französische Botschafter François Seydoux gegenüber Bundeskanzler Kiesinger: „Die französische Regierung sei der Meinung gewesen, und sei es auch heute noch, daß es zunächst Englands Sache sei, sich um die Annäherung an die Gemeinschaft zu bemühen. [...] Er, Seydoux, habe das neue deutsche Papier nur überfliegen können. Er habe aber den Eindruck, daß schon das Arrangement nicht in dem Sinne erörtert sei, wie es Frankreich gehofft habe. Besondere Schwierigkeiten würde wohl die Regelung für landwirtschaftliche Erzeugnisse machen. In der Technologie gingen gewisse Vorschläge sehr weit, auch hinsichtlich des Verfahrens“. Kiesinger entgegnete, daß ein Arrangement keine Deklaration "ohne politische Substanz" sein dürfe; „es müsse vielmehr wirklich einen Schritt nach vorn bedeuten“. Vgl. Bundeskanzleramt, AZ: 21-30 100 (56), Bd. 27; B 150, Aktenkopien 1968.

5 Zur EG-Ministerratstagung am 9. März 1968 in Brüssel vgl. Dok. 93. 
pieres. Er hielt eine Aussprache Brandts und Couves vor der Samstagsitzung für unbedingt erforderlich. Das deutsche Papier enthalte einige deutsche Interpretationen des Pariser Ergebnisses ${ }^{6}$ und darüber hinaus Vorschläge, die von anderen stammten. Soweit es über das Pariser Ergebnis hinausgehe, sei es nur als Diskussionsgrundlage zu betrachten. So sollte es auch in der Ministerratssitzung präsentiert werden. Eine Konfrontation der deutschen und der französischen Seite müsse vermieden werden. Auf diese Weise würde auch Zeit gewonnen.

Bundeskanzleramt, AZ: 21-30 100 (56), Bd. 27

91

\section{Aufzeichnung des Ministerialdirektors Ruete}

II A 7-81.08-2/579I/68 geheim

11. März 1968 ${ }^{1}$

Betr.: Militärische Ost-West-Kontakte

I. 1) In den letzten Monaten ist die Frage militärischer Ost-West-Kontakte aktuell geworden:

- Frankreich ist auf diesem Gebiet bisher am weitesten gegangen. Die Generalstabschefs Frankreichs und der Sowjetunion ${ }^{2}$ haben Besuche ausgetauscht; kleine Gruppen französischer und sowjetischer Fallschirmjäger (je 8 Soldaten) wurden zu gemeinsamen Veranstaltungen ausgetauscht; ein Besuchsund Erfahrungsaustausch auf rüstungswirtschaftlichem Gebiet wurde eingeleitet; ein französischer Zerstörer hat Leningrad besucht.

- Der belgische Verteidigungsminister ${ }^{3}$ hat Polen besucht, ein Besuchsaustausch von hohen Generalstabsoffizieren mit der Sowjetunion wird vorbereitet.

- Der Chef des kanadischen Generalstabs ${ }^{4}$ ist zu einem Besuch der Sowjetunion eingeladen.

- Der norwegische Verteidigungsminister ${ }^{5}$ hat die Sowjetunion besucht.

- Unsere eigenen militärischen Kontakte haben sich auf den Besuch eines sowjetischen Generalarztes im Bundeswehrlazarett Koblenz beschränkt. Der Besuch fand auf sowjetischen Wunsch im September 1967 im Anschluß an einen internationalen militärärztlichen Kongreß in München statt.

\footnotetext{
6 Für den Wortlaut der deutsch-französischen Erklärung vom 16. Februar 1968 vgl. Dok. 62, Anm. 17.

1 Durchdruck.

Die Aufzeichnung wurde vom Vortragenden Legationsrat Behrends und von Legationsrat Spalcke konzipiert.

Hat Vortragendem Legationsrat I. Klasse Lankes vorgelegen.

2 Charles Ailleret und Matwej Wassiljewitsch Sacharow.

3 Charles Poswick.

4 J. V. Allard.

5 Otto Grieg Tidemand.
} 
2) Die grundsätzliche Frage, wie weit militärische Kontakte der NATO-Staaten zu kommunistischen Staaten wünschenswert sind, wird in Kürze im Politischen Ausschuß der NATO untersucht werden. Unsere Stellungnahme wird an dem Kriterium orientiert sein müssen, ob diese militärischen Kontakte der Entspannung dienen, oder ob sie von der Sowjetunion als ein Mittel zur Isolierung Deutschlands von seinen Verbündeten benutzt werden können.

Diese Gefahr ist nicht zu unterschätzen. Die Sowjetunion scheint militärische Kontakte zu uns gegenwärtig nicht zu erwägen, sondern vor allem zu denjenigen NATO-Ländern anknüpfen zu wollen, die Deutschland benachbart sind und Streitkräfte in Deutschland unterhalten. Der Sowjetunion fällt es dabei leicht, an die Waffenbrüderschaft des Zweiten Weltkrieges anzuknüpfen und den gemeinsamen Kampf gegen den deutschen Militarismus herauszustellen.

Wir können deshalb militärische Ost-West-Kontakte der NATO-Staaten nur dann befürworten, wenn es uns gelingt, innerhalb der NATO eine gewisse Koordinierung dieser Kontakte zu erreichen.

Außerdem sollten wir uns bemühen, eigene Kontakte zu den Streitkräften der Sowjetunion und der osteuropäischen Staaten herzustellen. Dies setzt die Normalisierung der militärischen Beziehungen durch Austausch von Militärattachés mit den Oststaaten, zu denen wir diplomatische Beziehungen unterhalten, voraus. ${ }^{6}$

II. Es bestehen ständige Kontakte zwischen den Oberbefehlshabern der in Deutschland stationierten Streitkräfte der drei Westmächte und der Sowjetunion. Diese Kontakte, Überreste der Vier-Mächte-Verantwortung für Deutschland, finden in beiden Teilen Deutschlands ohne Beteiligung deutscher Stellen statt. Der Vermittlung dieser Kontakte dienen sowjetische Militärmissionen in Bünde (Westfalen), Frankfurt und Baden-Baden sowie Militärmissionen der drei Alliierten in Potsdam, die die Funktionen eines Verbindungsstabes zwischen den jeweiligen Oberbefehlshabern und ihren Generalstäben wahrnehmen. Sichtbarer Ausdruck der Pflege dieser Beziehungen sind die Antrittsund Abschiedsbesuche, die sich die vier Oberbefehlshaber noch heute abzustatten pflegen.

Diese Militärmissionen haben heute im wesentlichen nachrichtendienstliche Aufgaben. Außerdem bedienen sich die vier Oberbefehlshaber gelegentlich der Missionen, um bei Zwischenfällen (z. B. bei Störungen des militärischen Zugangs nach Berlin, bei Notlandungen von Militärflugzeugen oder bei Deserteuren) Kontakte herstellen zu können.

III. Seit der Eröffnung der deutschen Botschaft in Moskau im Jahre $1956^{7}$ ist die Frage eines Militärattachéaustausches mit der Sowjetunion wiederholt geprüft worden.

1) Unsere bis 1966 negative Haltung war von der Befürchtung bestimmt, daß die Sowjetunion den Austausch von Militärattachés zum Anlaß nehmen könnte, um ihre drei Militärmissionen in der Bundesrepublik Deutschland zurück-

6 Zu diesem Absatz handschriftliche Bemerkung des Vortragenden Legationsrats I. Klasse Lankes: ,ri[chtig]!“

7 Am 10. Januar 1956 nahm die Botschaft der Bundesrepublik in Moskau nach Erteilung des Agréments an Botschafter Haas ihre Tätigkeit auf. Vgl. dazu BuLletin 1956, S. 41. 
zuziehen und die Auflösung der drei alliierten Militärmissionen in Potsdam zu fordern.

Eine solche sowjetische Reaktion hätte in der Tat nachteilige Konsequenzen:

- Ein weiterer Restbestand der Vier-Mächte-Verantwortung für Deutschland würde beseitigt.

- Die drei Alliierten würden mit der Auflösung ihrer Militärmissionen in Potsdam eine wichtige nachrichtendienstliche Erkenntnisquelle ersatzlos verlieren.

- Bei Zwischenfällen in der SBZ (z.B. Notlandung alliierter Flugzeuge) wären die Alliierten voraussichtlich gezwungen, sich mit SBZ-Behörden in Verbindung zu setzen.

Solange es (in den Jahren 58-62) die erklärte Politik der Sowjetunion war, einen separaten Friedensvertrag mit der SBZ abzuschließen und alsbald die noch bestehenden Reste der Vier-Mächte-Verantwortung für Deutschland zu beseitigen, mußten diese möglichen Folgen eines Austausches von Militärattachés mit der Sowjetunion sehr ernstgenommen werden.

Abteilung II bezweifelt jedoch, ob diese Bedenken heute noch sehr gewichtig sind. Es sind keine Anzeichen dafür zu erkennen, daß die Sowjetunion ihre Zuständigkeit für Berlin und für den militärischen Zugang nach Berlin, die sie sich gegenüber der „DDR“ vorbehalten hat, aufgeben will. Solange dies nicht der Fall ist, hat sie ein eigenes Interesse daran, direkte Kontakte zu den drei alliierten Oberbefehlshabern zu unterhalten. Die Bemühungen der Sowjetunion, das Potsdamer Abkommen aufzuwerten, sprechen dafür, daß ihr durchaus daran gelegen ist, die noch bestehenden Rudimente der militärischen Kontrolle der Vier Mächte über Deutschland aufrechtzuerhalten. Außerdem könnte ein sowjetischer Militärattaché in Bonn die militärischen Informations- und Interventionsmöglichkeiten der drei Militärmissionen kaum ersetzen. ${ }^{8}$

Es ist daher nicht wahrscheinlich, daß der Austausch von Militärattachés mit der Sowjetunion das sowjetische Verlangen nach Auflösung der alliierten Militärmissionen zur Folge haben wird. Da diese Frage jedoch wesentliche Interessen unserer drei Verbündeten berührt, müßten diese konsultiert werden, ehe wir wegen des Austausches von Militärattachés an die Sowjetunion herantreten.

2) Die psychologischen und praktischen Schwierigkeiten, die mit dem Auftreten eines sowjetischen Militärattachés in der Bundesrepublik Deutschland und seiner deutschen Kollegen in der Sowjetunion verbunden sind, werden nicht unerheblich sein. Auf beiden Seiten sind Ressentiments zu überwinden.

In Bonn wird es aus Sicherheitsgründen und aus Gründen der Reziprozität nicht möglich sein, den sowjetischen Militärattaché in vollem Umfang an der sehr großzügigen, auf befreundete Staaten zugeschnittenen Betreuung der Militärattachés durch das Bundesministerium der Verteidigung teilhaben zu lassen. In Moskau hingegen wird unser Militärattaché sowjetischen Versuchen, ihn zu kompromittieren und ihn nachrichtendienstlicher Tätigkeit zu überführen, sowie Bemühungen, ihn möglichst oft mit dem Attaché der „DDR“ zu kon-

8 Zu diesem Satz handschriftliche Bemerkung des Vortragenden Legationsrats I. Klasse Lankes: „Altes Argument von II B $2^{\prime \prime}$. 
frontieren, zu begegnen haben. Außerdem werden unsere Verbündeten die deutsch-sowjetischen militärischen Kontakte sorgfältig und argwöhnisch beobachten. ${ }^{9}$ Wenn eine derartige Situation auch ein hohes Maß von Feingefühl verlangen wird, so erscheinen die genannten Hemmnisse jedoch nicht als unüberwindlich. Das Problem ist grundsätzlich das gleiche, das sich auch unseren Diplomaten stellt, wenn es auch durch die Uniform und die sehr ausgeprägte Kameraderie innerhalb des Militärattaché-Korps verschärft wird. ${ }^{10}$

3) Für den Austausch von Militärattachés mit der Sowjetunion und damit für die Aufnahme offizieller Beziehungen zwischen den deutschen und den sowjetischen Streitkräften lassen sich folgende Argumente anführen:

- Er entspricht unserer grundsätzlichen Politik, die Beziehungen zur Sowjetunion und den osteuropäischen Staaten auf allen Gebieten zu normalisieren.

- Er läge auf der Linie unseres in der Friedensnote vom März 1966 enthaltenen und in den sogenannten „14 Punkten“ im Juni 1967 wiederholten Vorschlags, den Austausch von Manöverbeobachtern mit den Ostblockstaaten zu vereinbaren. ${ }^{11}$ Wir würden es dem Osten erschweren, diesen Vorschlag als Propagandamanöver abzuqualifizieren. ${ }^{12}$

- Er würde die höchst unbefriedigende Situation, daß die drei sowjetischen Militärmissionen zur einseitigen Beobachtung des militärischen Geschehens in der Bundesrepublik Deutschland genutzt werden können, revidieren.

4) Wir können nicht ausschließen, daß die Sowjetunion einen deutschen Vorschlag, Militärattachés auszutauschen, zurückweisen wird. Wir sollten daher einen solchen Vorschlag diskret und als vorsichtige Sondierung vorbringen. Dieser Vorschlag sollte nicht als demonstrative politische Geste präsentiert werden, sondern als eine normale und lange überfällige Komplettierung der diplomatischen Beziehungen.

IV. 1) Es liegen Anzeichen vor, daß die Rumänen interne Überlegungen über einen Militärattaché-Austausch mit uns anstellen.

Wir sollten daher Bukarest gleichzeitig mit Moskau in sondierender Form die Entsendung eines Militärattachés anbieten. Bei der auf militärischem Gebiet nach wie vor engen Zusammenarbeit im Warschauer Pakt kann mit Sicherheit angenommen werden, daß die Frage des Austausches von Militärattachés dort diskutiert und abgestimmt wird. Man sollte die Rumänen daher von der gleichzeitigen Anfrage in Moskau unterrichten.

9 Zum Passus „In Moskau ... argwöhnisch beobachten“ handschriftliche Bemerkung des Vortragenden Legationsrats I. Klasse Lankes: „Da gibt es doch wohl Erfahrungen und Übung!“

$10 \mathrm{Zu}$ diesem Satz handschriftliche Bemerkung des Vortragenden Legationsrats I. Klasse Lankes: ${ }_{n}$ ri [chtig]!“

11 In der Note der Bundesregierung vom 25. März 1966 („Friedensnote“) wurde ausgeführt: „Um das Mißtrauen vor angeblichen deutschen Aggressionsabsichten zu zerstreuen, schlägt die Bundesregierung ferner bilaterale Vereinbarungen mit der sowjetischen, polnischen, tschechoslowakischen, ungarischen, rumänischen und bulgarischen Regierung über den Austausch militärischer Beobachter bei Manövern der Streitkräfte vor.“ Vgl. BULLETIN 1966, S. 331.

Bundesminister Brandt übergab dem sowjetischen Botschafter Zarapkin am 16. Juni 1967 ein 14 Punkte umfassendes Exposé, das Grundlage von Regierungsgesprächen sein sollte. Unter Punkt 12 wurde der Austausch von Manöverbeobachtern angeregt. Vgl. dazu AAPD 1967, II, Dok. 224.

$12 \mathrm{Zu}$ diesem Absatz handschriftliche Bemerkung des Vortragenden Legationsrats I. Klasse Lankes: „II B $2^{4}$. 
2) Im Falle Jugoslawien ist eine Rücksichtnahme auf die Sowjetunion kaum erforderlich, da Jugoslawien nicht Mitglied des Warschauer Pakts ist. Die Aufnahme diplomatischer Beziehungen wäre eine günstige Gelegenheit, den Austausch von Militärattachés ohne Aufsehen gleichzeitig mit der Errichtung der beiden Botschaften zu vollziehen.

Jugoslawien wird voraussichtlich daran interessiert sein, zumal dem jugoslawischen Botschafter in Bonn bis zum Abbruch der Beziehungen im Jahre $1957^{13}$ ein Offizier als informeller Militärattaché zugeteilt war. Dieser Offizier unterhielt engen Kontakt zum Bundesministerium der Verteidigung.

V. Abteilung II schlägt vor, das Bundesministerium der Verteidigung davon zu unterrichten, daß das Auswärtige Amt den Austausch von Militärattachés mit der Sowjetunion, Rumänien und Jugoslawien erwägt. Das Bundesministerium der Verteidigung sollte um baldige Stellungnahme zu diesem Vorschlag gebeten werden.

Im Falle einer positiven Reaktion des Bundesministeriums der Verteidigung zur Frage des Militärattachéaustausches wäre folgendes zu unternehmen:

1) Konsultation der drei Verbündeten in der Bonner Vierergruppe über die Entsendung eines deutschen Militärattachés nach Moskau.

2) Falls diese zustimmen: Sondierung bei den Sowjets und Rumänen.

3) Etwa gleichzeitig mit der Aktion gegenüber der Sowjetunion und Rumänien sollte mit den Jugoslawen ein Gespräch über den Austausch von Militärattachés eingeleitet werden.

VI. Ferner sollten mit dem Bundesministerium der Verteidigung folgende Möglichkeiten militärischer Kontakte erörtert werden:

1) Fortführung des bereits bestehenden Kontaktes mit der Sowjetunion auf militärärztlichem Gebiet.

2) Intensivierung militärsportlicher Beziehungen zu den Staaten Ost-Europas im Rahmen des CISM (Conseil International de Sport Militaire), z. B. durch Aufnahme der Sowjetunion und anderer osteuropäischer Staaten in den CISM oder durch Einladung osteuropäischer Staaten zu Veranstaltungen des CISM sowie Teilnahme der Bundeswehr an militärsportlichen Veranstaltungen des Ostblocks.

Abteilung $\mathrm{V}$ hat mitgezeichnet.

Hiermit über den Herrn Staatssekretär ${ }^{14}$ dem Herrn Bundesminister mit der Bitte um Zustimmung vorgelegt.

VS-Bd. 4351 (II B 2)

gez. Ruete

\footnotetext{
13 Korrigiert aus: „1958“.

Als Reaktion auf die Aufnahme diplomatischer Beziehungen zwischen der DDR und Jugoslawien brach die Bundesrepublik am 19. Oktober 1957 die Beziehungen zu Jugoslawien ab.

14 Georg Ferdinand Duckwitz.
} 